UNIVERSIDADE DE SÃO PAULO

ESCOLA DE EDUCAÇÃO FÍSICA E ESPORTE DE RIBEIRÃO PRETO

VITOR MARQUETI ARPINI

Efeitos de um protocolo de HIIT curto na cinemática dos membros inferiores em praticantes recreacionais de exercício físico 
VITOR MARQUETI ARPINI

\title{
Efeitos de um protocolo de HIIT curto na cinemática dos membros inferiores em praticantes recreacionais de exercício físico
}

\author{
Versão Corrigida
}

Dissertação apresentada à Escola de Educação Física e Esporte de Ribeirão Preto da Universidade de São Paulo, para obtenção do título de Mestre em Ciências, Programa de Pós-Graduação em Educação Física e Esporte.

Área de Concentração: Aspectos biodinâmicos da atividade física e do esporte

Orientador: Prof. Dr. Paulo Roberto Pereira Santiago

Ribeirão Preto - SP 
Autorizo a reprodução e divulgação total ou parcial deste trabalho, por qualquer meio convencional ou eletrônico, para fins de estudo ou pesquisa, desde que citada a fonte.

Catalogação na publicação

Serviço de Biblioteca e Documentação

Escola de Educação Física e Esporte de Ribeirão Preto

\section{Arpini, Vitor Marqueti}

Efeitos de um protocolo de HIIT curto na cinemática dos membros inferiores em praticantes recreacionais de exercício físico/Vitor Marqueti Arpini; orientador, Paulo Roberto Pereira Santiago. - 2020

$41 \mathrm{f}$.

Dissertação (Mestrado em Educação Física) - Programa de Pós-Graduação em Educação Física e Esporte, Universidade de São Paulo, Ribeirão Preto, 2020

Versão Corrigida

1. Treinamento Intervalado de Alta Intensidade. 2. Cinemática. 3. Corrida. I. Santiago, Paulo Roberto Pereira, oriente. II. Título. 


\section{DEDICATÓRIA}

É com enorme gratidão e amor que dedico este trabalho à minha esposa, que nunca desistiu de mim, mesmo com a distância e contratempos, sempre acreditou que eu conseguiria, independente das circunstâncias. Aos meus pais que sempre me apoiaram em todas as minhas decisões e essa talvez tenha sido a mais difícil de todas até agora, não medindo esforços para que pudesse concluir essa tão importante etapa em minha vida. 


\section{AGRADECIMENTOS}

Primeiramente, gostaria de agradecer infinitamente à Deus, que me dá o dom da vida todos os dias, me dando a oportunidade de encarar esse desafio com determinação e força. Sem Ele, não estaria escrevendo essas palavras.

Coladinho a Ele, agradeço com toda minha força e amor à minha maravilhosa esposa, Mariana Favato Lorenzoni, que foi parceira fiel e compreensiva, ao longo dessa jornada tortuosa. Teamo.

Aos meus pais Luiz e Luzia, fonte de generosidade e confiança, as quais depositaram a mim e nunca duvidaram do meu sucesso, além do amor, carinho e preocupação que sempre demonstraram, direta ou indiretamente.

Ao meu orientador Prof. Dr. Paulo Roberto Santiago, pela oportunidade a mim concedida, com seu jeito ímpar e reconhecidamente acolhedor, apesar dos erros e falhas durante o processo até aqui.

Aos meus grandes amigos feitos em Ribeirão Preto, Bruno (Bedo), Rodrigo (Dinei), Rafael (Japa), Luiz (Nerd), Carlos (Beisso), Isabella (Harry) e Thiago (Barretos), que ultrapassaram os limites da USP, construindo uma amizade duradoura e sincera.

À todos os colegas do Laboratório de Biomecânica e Controle Motor (LabioCoM) por nunca pouparem esforços para me ajudar, principalmente, Eduardo Bergonzoni.

Aos professores da EEFERP que me auxiliaram e compartilharam um pouco do seu conhecimento comigo.

Aos voluntários que toparam participar dessa pesquisa nada fácil.

A Coordenação de Aperfeiçoamento de Pessoal de Nível Superior (CAPES) pelo apoio concedido (Código de Financiamento 001) para o desenvolvimento parcial deste projeto, juntamente com a Fundação de Amparo à Pesquisa do Estado de São Paulo (FAPESP) que também colaborou com essa trajetória. 


\section{RESUMO}

ARPINI, Vitor Marqueti. Efeitos de um protocolo de HIIT curto na cinemática dos membros inferiores em praticantes recreacionais de exercício físico. 2020. $42 \mathrm{f}$. Dissertação (Mestrado em Educação Física e Esporte) - Escola de Educação Física e Esporte de Ribeirão Preto da Universidade de São Paulo, Ribeirão Preto, 2020.

O Treinamento Intervalado de Alta Intensidade ou High Intensity Interval Training (HIIT), em comparação aos treinamentos aeróbios tradicionais, tem se mostrado mais eficaz por proporcionar resultados rápidos e ter duração reduzida. Contudo, existe uma preocupação com as alterações cinemáticas e com o que essas modificações podem estar associadas. Portanto, o presente estudo teve como objetivo analisar os efeitos de uma sessão aguda de HIIT sobre parâmetros cinemáticos dos membros inferiores, em praticantes recreacionais de exercício físico. Dezoito voluntários $(24,16 \pm 3,47$ anos; $79,53 \pm 6,98 \mathrm{~kg} ; 179,48 \pm 6,34 \mathrm{~cm}$ ) praticantes de exercício físico por, no máximo, três vezes por semana, realizaram uma sessão de HIIT curto, que consistiu em esforços à $120 \%$ da velocidade pico em esteira, obtida pelo teste incremental, com estímulo:recuperação de 30s:15s, até a exaustão voluntária máxima. Foram analisados os ângulos de tornozelo, joelho e quadril, do primeiro e último sprint, pelo teste t de Student para amostras pareadas utilizando o método Statistical Parametric Mapping (SPM) de análise estatística. Os principais achados somente evidenciam redução da dorsiflexão de ambos os tornozelos, ao final dos sprints. Portanto, os achados da presente pesquisa mostraram que realizar um protocolo de HIIT curto até a exaustão voluntária, de modo geral, não altera a cinemática dos membros inferiores, em praticantes recreacionais de exercício físico.

Palavras-chaves: corridas; esforços; alta intensidade; exercício intervalado; exaustão. 


\section{ABSTRACT}

ARPINI, Vitor Marqueti. Effects of a short HIIT protocol on lower limb kinematics in recreational physical exercise practitioners. 2020. 42 f. Dissertação (Mestrado em Educação Física e Esporte) - Escola de Educação Física e Esporte de Ribeirão Preto da Universidade de São Paulo, Ribeirão Preto, 2020.

High-Intensity Interval Training (HIIT), when compared to traditional aerobic training, has shown efficient to performance even with short duration. However, there is a concern about kinematic changes during high-intensity running and what these changes can cause to runners. Therefore, the present study aimed to analyze the effects of HIIT acute session on kinematics parameters in recreational males practitioners of exercises, with different ability to repeated sprints. Eighteen recreational males runners $(24.16 \pm 3.47$ years; 79.53 $\pm 6.98 \mathrm{~kg} ; 179.48 \pm 6.34 \mathrm{~cm}$ ) with practicing physical activity for less than three times a week. All participants performed a short HIIT session which consists of on efforts up to $120 \%$ of the maximum speed on the treadmill, during the incremental test, with stimulus: recovery 30s15s, until a maximum voluntary exhaustion. The ankle, knee and hip angles of the first and last sprint were analyzed using the Statistical Parametric Mapping (SPM) method of statistical analysis. The main findings only show a reduction in the dorsiflexion of both ankles at the end of the sprints. Therefore, the findings of the present study showed that performing a short HIIT protocol until voluntary exhaustion, in general, does not alter the lower limb kinematics in recreational physical exercise practitioners.

Keywords: high intensity; interval exercise; fatigue; exhaustion. 


\section{LISTA DE FIGURAS}

Figura 1. Características dos tipos de HIIT.

Figura 2. Organograma Revisão de literatura.

Figura 3. Aquecimento (A), realização do esforço do protocolo HIIT (B), recuperação passiva do protocolo HIIT (C).

Figura 4. Marcadores utilizados no momento da coleta (A e B) e reconstrução 3D realiza no software Motive (C).

Figura 5. Representação dos sistemas da pelve, coxa, perna e pé.

Figura 6. Resultado dos ângulos do tornozelo direito. 25

Figura 7. Resultado dos ângulos do tornozelo esquerdo. 26

Figura 8. Resultado dos ângulos do joelho direito. 26

Figura 9. Resultado dos ângulos do joelho esquerdo. 27

Figura 10. Resultado dos ângulos do quadril direito. 27

Figura 11. Resultado dos ângulos do quadril esquerdo. 28 


\section{LISTA DE TABELAS}

Tabela 1. Artigos selecionados após os critérios de seleção.

16

Tabela 2. Média e desvio padrão da PSE dos voluntários, no primeiro e último sprint

22

Tabela 3. Movimentos angulares. 


\section{LISTA DE ABREVIATURAS E SIGLAS}

CI Contato inicial

CONT Exercício contínuo

EC Economia de corrida

HIIT High Intensity Interval Training

INT Exercício Intervalado

Lan Limiar anaeróbio

MVA Máxima velocidade aeróbia

PDP Padrão de pisada

RST Repeated Sprint Training

SIT Sprint Interval Training

SPM Statistical Parametric Mapping

TMAX Tempo máximo

$\dot{V} O_{2 M A ́ x} \quad$ Consumo máximo de oxigênio

$\dot{V} \mathrm{O}_{2 \text { pico }} \quad$ Consumo pico de oxigênio

VPE Velocidade pico em esteira

v $\dot{V} \mathrm{O}_{2 \mathrm{MÁx}} \quad$ Velocidade associada ao consumo máximo de oxigênio 


\section{SUMÁRIO}

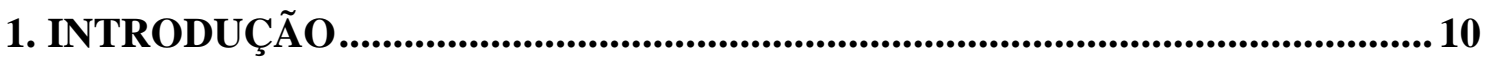

1.1 Enquadramento e Justificativa ..................................................................................10

1.2 Revisão de Literatura.........................................................................................12

1.2.1 HIIT e suas variáveis..................................................................................12

1.2.2 Seleção dos artigos .................................................................................................14

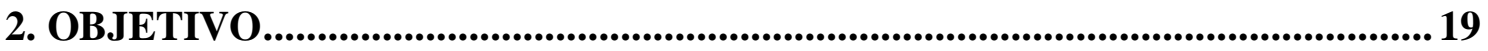

3. PROCEDIMENTOS METODOLÓGICOS .......................................................20

3.1 Participantes.....................................................................................................................20

3.2 Procedimento experimental ................................................................................ 20

3.3 Determinação da velocidade pico em esteira.............................................................20

3.4 Protocolo de Treinamento Intervalado de Alta Intensidade ..................................21

3.5 Aquisição dos dados ...............................................................................................21

3.6 Processamento dos dados................................................................................................22

3.7 Análise Estatística ..........................................................................................................24

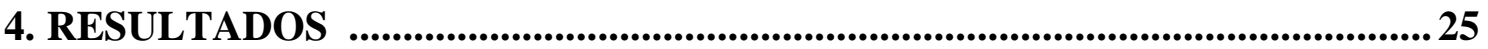

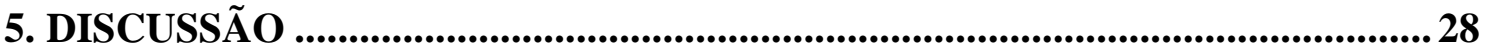

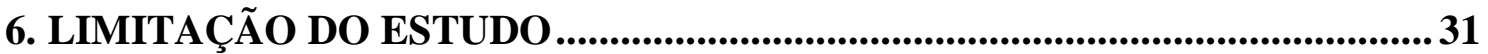

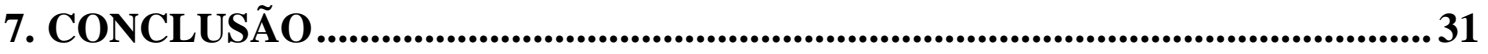

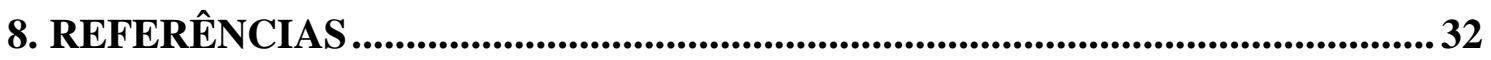

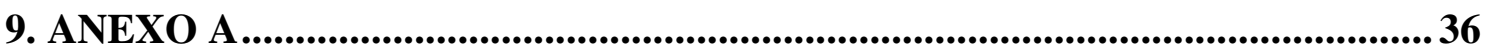

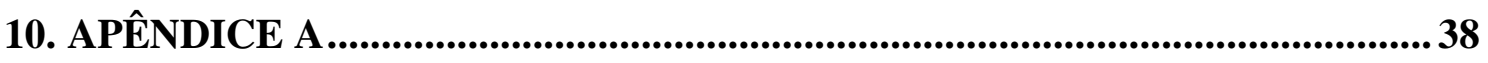

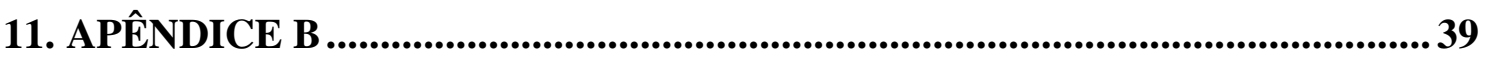




\section{INTRODUÇÃO}

\subsection{Enquadramento e justificativa}

O Treinamento Intervalado de Alta Intensidade, em inglês High Intensity Interval Training (HIIT), tem sido amplamente adotado para melhora de rendimento físico (BILLAT, 2001a, 2001b, BUCHHEIT; LAURSEN, 2013a, 2013b). Esse meio de treinamento consiste na realização de um exercício com alta intensidade, normalmente o mais próximo ou excedendo $100 \%$ do Consumo Máximo de Oxigênio ( $\dot{V} O_{2 M A ́ X}$ ). A relação estímulo:recuperação é proporcional e alternado, independente do exercício realizado, seja ele cíclico ou não (BROOKS, 1998; FOX; BOWERS; MERLE, 1992; LAURSEN; JENKINS, 2002).

A proposta do HIIT é induzir alterações metabólicas e de desempenho similares ou maiores em relação ao treinamento aeróbio tradicional, além de proporcionar resultados razoavelmente mais rápidos e a sessão de exercício ter duração reduzida (LITTLE, 2010; GIBALA et al., 2012; HEYDARI, 2012; KEATING, 2014; ZWESLOOT et al., 2014). Para comprovar tais benefícios, Esfarjani e Laursen, (2007) compararam os efeitos de dois protocolos de HIIT (i.e., Grupo 1: 8 x 60\% do Tempo Máximo (T $\mathrm{T}_{\mathrm{MAX}}$ ), 1:1; Grupo

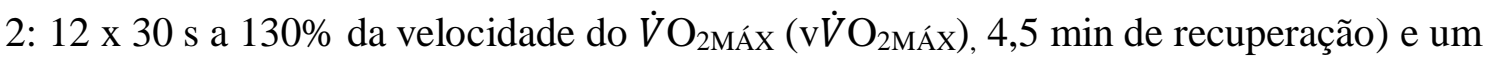
de treinamento aeróbio contínuo (i.e., Grupo 3: $60 \mathrm{~min}$ a $70 \%$ v $\dot{V} \mathrm{O}_{2 \mathrm{MÁx}}$ ) durante 10 semanas. Eles verificaram que os protocolos de HIIT resultaram em efeitos positivos

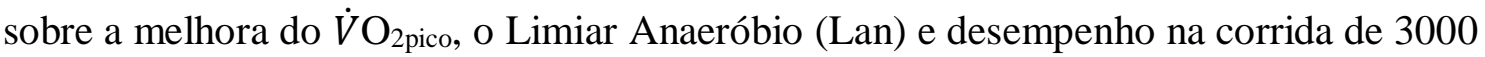
m, do que o treinamento aeróbio contínuo. Em complemento, as revisões sistemáticas de Sloth et al., (2013) e Gist et al., (2014), evidenciam que o Treinamento Intervalado de Sprint (SIT), outro tipo de HIIT, melhoram a capacidade aeróbia, utilização de substratos durante a recuperação e principalmente, utilizam de um menor volume de treino para que esses benefícios ocorram.

Além da contribuição para a melhoria do condicionamento aeróbio e anaeróbio, o HIIT também tem sido implementado em programas de treinamento objetivando o gasto calórico e oxidação de lipídios (LANFORGIA et al., 1987; TREMBLAY; SIMONEAU; BOUCHARD, 1994; TURCOTTE, 1995; FERNANDEZ et al., 2004; DARLING; LINDERMAN; LAUBACH, 2005). Boutcher, (2011) indicaram que a prática regular de HIIT além de ter apresentado ótima relação à redução de gordura subcutânea e abdominal para mulheres jovens, também contribui para atenuação de patologias metabólicas existentes, como, redução da resistência à insulina e níveis glicêmicos em indivíduos com 
diabetes tipo II, principalmente quando utilizado o SIT como estímulo. Resultados similares foram encontrados por Ross, Porter e Durstine, (2016), na qual os autores classificaram o HIIT como ótimo meio para melhoria cardiovascular (ex., melhor volume de ejeção), capacidade funcional respiratória e redução mais rápida da glicemia em conjunto com uma maior oxidação de massa gorda em pacientes com diabetes tipo II. Estudos anteriores confirmam esta revisão, apresentando melhorias em condições patológicas com a utilização do HIIT (CUNNINGHAM; MCCRIMMON; VLACH, 1979; MORENO; LIBERALI; NAVARRO, 2009; MARCINKO et al., 2015).

Entretanto, mesmo com as contribuições do HIIT para melhoria da capacidade respiratória, redução de gordura corporal e de doenças metabólicas e cardíacas, há uma preocupação nos efeitos que os esforços intensos e repetitivos desse tipo de exercício podem provocar na estrutura física dos praticantes. Estudos já mostraram que modificações cinemáticas na corrida contínua podem sobrecarregar articulações e tecidos moles (MILNER; HAMILL; DAVIS, 2007; GALLO; PLAKKE; SILVIS, 2012; LATORRE-ROMÁN et al., 2015). Como exemplo, Hreljac, (2004) destacou que, na corrida, o impacto sobre os membros inferiores geralmente é maior à medida que a velocidade aumenta, podendo ocasionar lesões por excesso de treinamento, tais como, fratura por estresse, condromalácia patelar e tendinite do tendão de Aquiles. Posteriormente, Whiting e Zernicke, (2009) evidenciaram que pessoas jovens podem sofrer fratura de estresse no fêmur proximal como resultado de cargas repetidas suportadas durante atividades extenuantes. Os autores afirmam também que sobrecargas articulares repetitivas podem ser um fator de risco preditivo para osteoartrite do quadril, Síndrome do Estresse Tibial Medial e desgastes meniscais. Mais recentemente, Winkelmann et al., (2016) evidenciaram que a Síndrome do Estresse Tibial (comum em corredores) não está relacionada somente com a inflamação do periósteo, mas também ao aumento da rotação do quadril, aumento da flexão plantar e pronação dos tornozelos.

Dentre os fatores que podem resultar em alterações cinemáticas prejudiciais para os corredores, como as citadas acima, destaca-se o estado de exaustão dos praticantes durante o exercício físico (KOBLBAUER et al., 2014). Mizrahi et al., (2000) investigou o efeito da exaustão em corredores recreacionais de longas distâncias sobre a aceleração de impacto da perna, taxa de passada, ângulo de joelho e a movimentação vertical do quadril. Os pesquisadores utilizaram acelerômetros para medir os impactos da perna e a cinemática 2D para encontrar o ângulo do joelho, a taxa da passada e a movimentação vertical do quadril. Os resultados encontrados mostraram que ao fim do protocolo de 30 
min, houve aumento do impacto da perna, redução da taxa de passada, aumento da movimentação vertical do quadril e aumento da extensão do joelho antes do contato com o solo e redução da amplitude da flexão do joelho durante o contato do pé ao solo. Os autores confirmam que todas as alterações estão relacionadas ao estado de exaustão e que essas modificações podem ser fatores de desenvolvimento de lesões por sobrecarga.

Em contrapartida, Derrick, Dereu e Mclean, (2002), averiguaram os ajustes cinemáticos no impacto da perna no instante do contato e na atenuação desse impacto durante uma corrida até a exaustão. Foram utilizados acelerômetros e eletro goniômetros para mensurar o impacto da perna, ângulo do joelho e tornozelo, respectivamente. Como resultado, apesar de terem encontrado aumento na aceleração do pico de impacto da perna, tal modificação não foi considerada um risco lesivo, pois como houve uma maior inversão do tornozelo e aumento da flexão do joelho no momento da pisada, acarretava em uma menor massa efetiva durante o contato, reduzindo o impacto pela perna. Todas essas alterações também foram relacionadas ao estado de exaustão durante a corrida.

Percebendo a influência da exaustão durante o exercício, mais especificamente na biomecânica da corrida, e com a grande prescrição dos exercícios utilizando o HIIT como meio de treinamento, a literatura nos apresenta alguns autores que investigaram as variáveis biomecânicas quando realizado o HIIT na corrida. Buscando compreender melhor tais pesquisas, foi realizado uma revisão com o objetivo de identificar o que existe na literatura sobre determinado assunto.

\subsection{Revisão de literatura}

\subsubsection{HIIT e suas variáveis}

O HIIT tem sido utilizado por atletas a quase uma década. Desde 1920 com Paavo Nurmi, um dos melhores corredores de médias e longas distâncias do mundo à sua época, o qual já utilizava algumas formas de HIIT em suas rotinas de treino, até Emil Zatopek, que contribuiu para a popularização desse tipo de treinamento nos anos 50. Por volta de 1960, o pesquisador Astrand e colaboradores publicaram artigos mais relevantes sobre as respostas agudas fisiológicas do HIIT, o que gerou a primeira base científica para o entendimento do HIIT longo e HIIT curto (BUCHHEIT; LAURSEN, 2013a). Além desses dois modelos ainda existem o Repeated Sprint Training (RST) e o Sprint Interval Training (SIT) (Figura 1). 
Figura 1. Tipos de HIIT e suas características

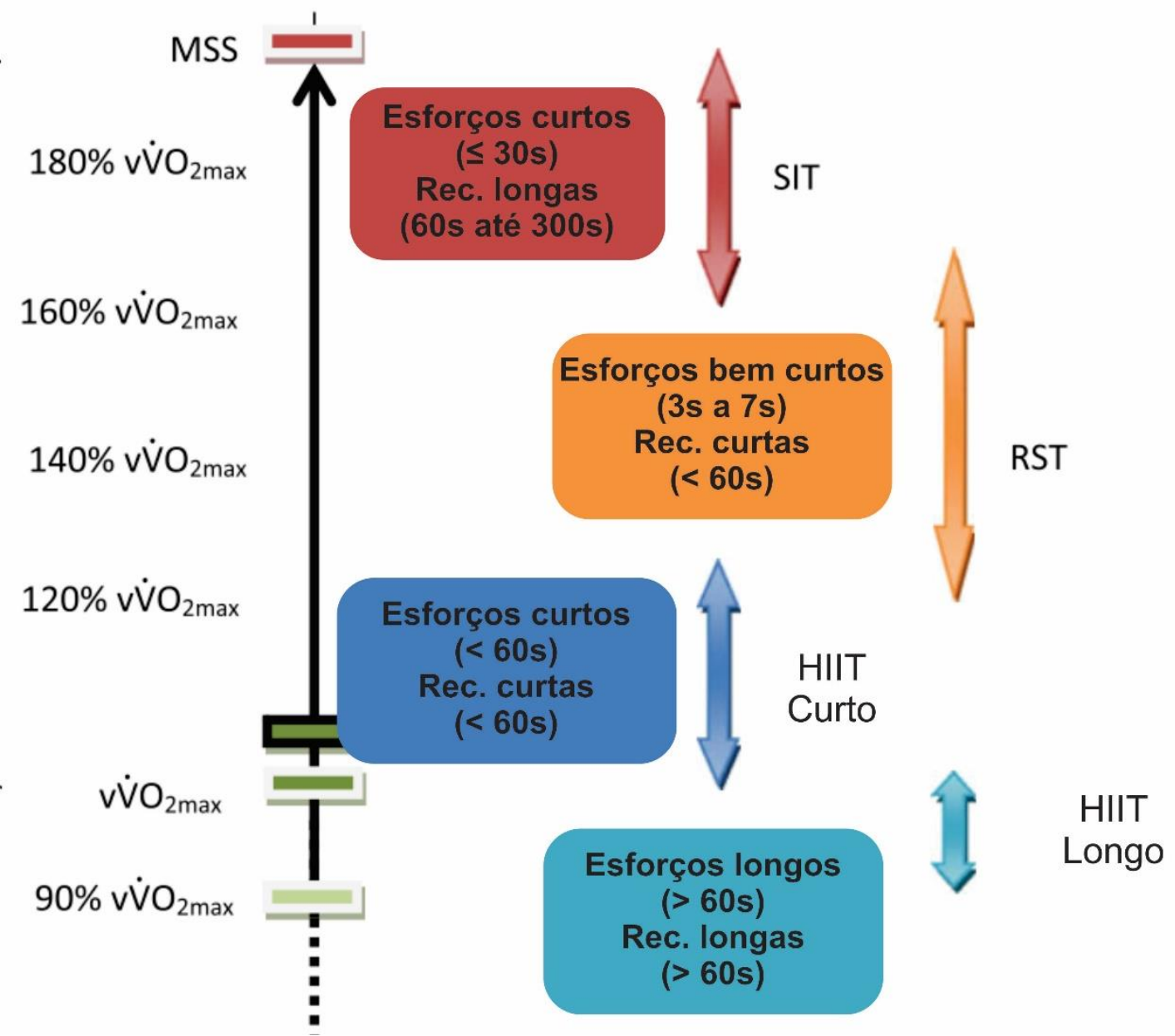

Fonte: Buchheit e Laursen (2013a), modificado pelo autor.

Em seu artigo, Buchheit e Laursen, (2013a), além de definirem os quatro tipos de HIIT (HIIT Longo, HIIT Curto, RST e SIT) também apresentam as nove variáveis que devem ser controladas durante a prescrição desse método de treinamento, são elas: i) intensidade do exercício; ii) modalidade do exercício; iii) duração do exercício; iv) intensidade da recuperação; v) duração da recuperação; vi) número de séries; vii) tempo entre as séries; viii) intensidade de recuperação entre as séries; ix) duração das séries. Desta forma, percebe-se a grande variedade de treinos que podem ser elaborados, manipulando os tipos de HIIT e suas variáveis. Variedade essa que, por muitas vezes, impossibilita uma comparação entre estudos, pois cada pesquisa utiliza um tipo de metodologia, como veremos a seguir. 


\subsubsection{Seleção dos artigos}

O HIIT é encontrado na literatura com diversas nomenclaturas e pouca investigação relacionada com a biomecânica. Devido a isso, foi realizado uma busca nas bases de dados PubMed - NCBI e Web of Science combinando os seguintes descritores: HIIT, Interval Training, High Intensity Training, Interval Running e Intermittent Exercise atrelados aos descritores da biomecânica: Kinematics, Biomechanics e Mechanics (Figura 2). Após as primeiras buscas, totalizaram-se 2021 artigos encontrados. Posteriormente, filtrados manualmente, com base no título e resumo, foram excluídos os estudos duplicados e que apresentavam os seguintes assuntos: biomecânica ou mecânica da corrida contínua; amostra composta apenas por participantes do gênero feminino; amostra composta por participantes com patologias ortopédicas e/ou metabólicas; análises biomecânicas dos membros superiores e estudos que não incluíam as seguintes variáveis: a) análise angular das articulações dos membros inferiores, associados à exercícios intervalados de alta intensidade. Após aplicação dos critérios descritos acima, foram retidos quatro estudos que estão apresentados na Tabela 1. 
Figura 2. Organograma Revisão de literatura

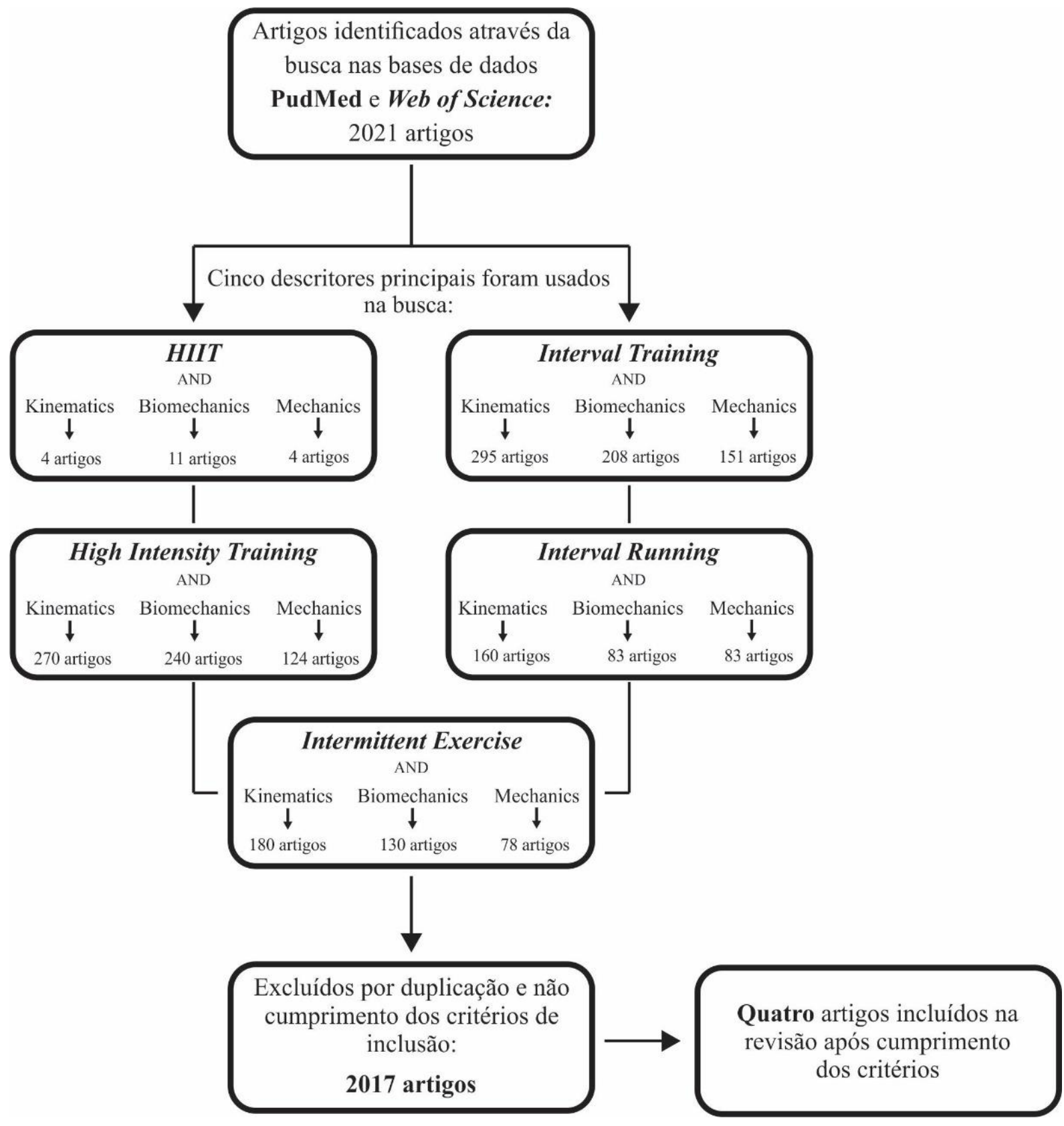


Tabela 1. Artigos selecionados após os critérios de seleção.

\begin{tabular}{|c|c|c|c|c|c|}
\hline Estudo & Participantes & Objetivos & Protocolo do Exercício & $\begin{array}{c}\text { Método } \\
\text { Cinemático }\end{array}$ & Principais Resultados \\
\hline $\begin{array}{l}\text { Latorre- } \\
\text { Román et } \\
\text { al. (2016) }\end{array}$ & $\begin{array}{l}13 \text { corredores } \\
\text { homens } \\
\text { de longa distancias, } \\
\text { altamente treinados. }\end{array}$ & $\begin{array}{l}\text { Avaliar a cinemática e o padrão } \\
\text { de pisada (PDP), após exaustão } \\
\text { induzida pelo HIIT. }\end{array}$ & $\begin{array}{l}5 \text { x } 2000 \mathrm{~m}, 120 \mathrm{~s} \text { rec passiva } \\
\text { Intensidade: máxima velocidade }\end{array}$ & $\begin{array}{l}\text { Cinemática } \\
2 \mathrm{D}\end{array}$ & $\begin{array}{l}\text { - Não foram encontradas diferenças substanciais na cinemática } \\
\text { nem no PDP, após a exaustão induzida pelo HIIT, observada } \\
\text { somente mínimo desalinhamento significante do tornozelo. }\end{array}$ \\
\hline $\begin{array}{l}\text { Collins et } \\
\text { al. (2000) }\end{array}$ & $\begin{array}{l}7 \text { corredores } \\
\text { homens de longa } \\
\text { distancias, } \\
\text { altamente treinados }\end{array}$ & $\begin{array}{c}\text { - Determinar se ocorre alterações } \\
\text { cinemáticas no padrão de corrida } \\
\text { após HIIT } \\
\text { - Estabelecer relação entre o } \\
\text { tempo de recuperação e possíveis } \\
\text { mudanças na cinemática; } \\
\text { - Relacionar se as mudanças na } \\
\text { Economia de Corrida (EC) estão } \\
\text { relacionadas com mudanças da } \\
\text { cinemática }\end{array}$ & $\begin{array}{l}\text { Teste de EC antes e após as sessões. } \\
\quad 3 \text { sessões de HIIT: } \\
\text { 1. } 10 \times 400 \mathrm{~m}, 1 \mathrm{~min} \text { rec ativa } \\
\text { 2. } 10 \times 400 \mathrm{~m}, 2 \mathrm{~min} \text { rec ativa } \\
\text { 3. } 10 \times 400 \mathrm{~m}, 3 \mathrm{~min} \text { rec ativa } \\
\text { Intensidade: Velocidade associada ao } \\
\text { VO2 reduzindo } 4 \% \text {. }\end{array}$ & $\begin{array}{l}\text { Cinemática } \\
2 \mathrm{D}\end{array}$ & $\begin{array}{c}\text { - Após as sessões de HIIT houve aumento do VO2, } \\
\text { independente do tempo de rec } \\
\text { - Redução da EC após o HIIT } \\
\text { - Independente do tempo de rec, a cinemática da corrida } \\
\text { permaneceu inalterada }\end{array}$ \\
\hline $\begin{array}{l}\text { García- } \\
\text { Pinillos et } \\
\text { al. }(\mathbf{2 0 1 6})^{\mathrm{a}}\end{array}$ & $\begin{array}{l}28 \text { homens } \\
\text { corredores de longa } \\
\text { distâncias, treinados }\end{array}$ & $\begin{array}{l}\text { Descrever as alterações } \\
\text { cinemáticas que ocorrem durante } \\
\text { uma sessão de HIIT. }\end{array}$ & $\begin{array}{l}3 \text { x } 4 \text { x } 400 \mathrm{~m}, 1 \text { min rec passiva entre os } \\
\text { esforços e } 3 \text { min rec entre as séries. } \\
\text { Intensidade: máxima velocidade }\end{array}$ & $\begin{array}{l}\text { Cinemática } \\
2 \mathrm{D}\end{array}$ & $\begin{array}{c}\text { - Para o grupo total, nenhuma diferença significativa foi } \\
\text { encontrada } \\
\text { - Para os grupos baseados em suas velocidades (mais rápidos x } \\
\text { mais lentos) foram encontradas diferenças nos ângulos de } \\
\text { quadril e joelho no momento da retirada do pé } \\
\text { - Para os grupos baseados no nível de exaustão alcançada } \\
\text { (Exausto x Não Exausto), também foram encontradas diferenças } \\
\text { nos ângulos de quadril e joelho na retirada do pé. }\end{array}$ \\
\hline $\begin{array}{l}\text { García- } \\
\text { Pinillos et } \\
\text { al. }(\mathbf{2 0 1 6})^{b}\end{array}$ & $\begin{array}{l}18 \text { homens } \\
\text { corredores } \\
\text { recreacionais de } \\
\text { longas distâncias }\end{array}$ & $\begin{array}{l}\text { Avaliar as características da } \\
\text { cinemática de corrida durante o } 1^{\circ} \\
\text { e último estágio de dois } \\
\text { protocolos de HIIT, com carga } \\
\text { externa similar porém com } \\
\text { diferente ritmo de corrida }\end{array}$ & $\begin{array}{c}\text { Protocolo 1: } \\
-10 \text { x } 400 \mathrm{~m}, 90-120 \mathrm{~s} \text { de rec passiva } \\
\text { Intensidade: aprox. } 107 \% \text { da velocidade } \\
\text { associada ao VO2MÁX } \\
\text { Protocolo } 2 \text { : } \\
\text { - } 40 \text { x } 100 \mathrm{~m}, 25-30 \mathrm{~s} \text { de rec passiva } \\
\text { Intensidade: aprox. } 125 \% \text { da velocidade } \\
\text { associada ao VO2MÁX }\end{array}$ & $\begin{array}{l}\text { Cinemática } \\
2 \mathrm{D}\end{array}$ & $\begin{array}{l}\text { - Não foram encontradas diferenças na cinemática de corrida } \\
\text { quando comparados o } 1^{\circ} \text { e últimos estágios de cada protocolo. } \\
\text { - Quando comparados os } 1^{\circ} \text { sprints entre os protocolo, foi } \\
\text { revelada uma influência da velocidade no protocolo } 2 \text {, } \\
\text { evidenciando menor tempo de contato e fase aérea e maior } \\
\text { comprimento de passo. Aumento na flexão do quadril e extensão } \\
\text { do tornozelo no contato inicial. Menor flexão de joelho e } \\
\text { tornozelo no meio do passo; e maior extensão de quadril na } \\
\text { retirada do pé, quando comparado com o protocolo } 1\end{array}$ \\
\hline
\end{tabular}


Dentre os quatro estudos selecionados, três avaliaram participantes treinados. Sabese que existe uma relação entre a mecânica da corrida e o nível de treinamento dos corredores, como demonstrado no estudo de Maas et al., (2018), na qual foi percebido uma maior inclinação do tronco a frente e maior abdução do quadril durante a fase de balanço, no grupo de corredores inexperientes em relação ao grupo de corredores competitivos. Isso mostra que os corredores menos experientes apresentaram maiores ajustes cinemáticos. Portanto, o presente trabalho utiliza-se de voluntários praticantes recreacionais de exercício físico, afim de compreender melhor o que ocorre em sua cinemática dos membros inferiores durante um exercício até a exaustão. Destaca-se ainda que os estudos majoritariamente utilizaram de análises bidimensional (2D) como método cinemático. Contudo, limitar sua perspectiva somente em um plano de movimento (sagital) pode nos fornecer dados incompletos do que realmente ocorre com as articulações. Isto posto, presente estudo utilizou o método 3D, o qual também observa as rotações e movimentos laterais das articulações dos membros inferiores.

Uma grande limitação da utilização do HIIT como foco de análise são seus diversos protocolos, como visto acima, o que dificulta a comparação entre os estudos (BUCHHEIT; LAURSEN, 2013a), uma vez que a modulação de variáveis como intensidade, volume e recuperação podem alterar sua repercussão na mecânica de corrida do indivíduo, como visto nos artigos apresentados na Tabela 1.

Sendo assim, para entendermos melhor os resultados até aqui encontrados na literatura, é necessário aprofundar nos artigos supracitados. Seguindo uma ordem cronológica, temos o trabalho de Collins et al., (2000), que após seu protocolo (10 x 400 m), não encontrou alterações importantes na flexão máxima do joelho e a velocidade do joelho durante a fase de suporte, o ângulo máximo de flexão plantar no momento da retirada do pé, ângulo da perna no momento do contato, ângulo do tronco durante o ciclo do passo, oscilação vertical do centro de massa e comprimento do passo. Os autores evidenciaram alterações quando há a comparação entre os corredores, justificando que alguns indivíduos são mais sensíveis ao estado de exaustão, realizando algumas compensações para tentar manter o padrão da corrida, porém, dessa forma, alterando sua cinemática (SILER; MARTIN, 1991).

Corroborando com os achados supracitados, Latorre-Roman et al., (2016), também não encontraram diferenças significantes, após um protocolo de HIIT (5 x 2000 m), nas variáveis angulares (joelho e tornozelo), comprimento do passo, soma das distâncias de saída, fase aérea e de contato e o padrão de contato do pé com o chão. Os autores 
apontaram que mesmo sob estado de exaustão, os corredores não modificaram seu pace nem sua cinemática de corrida e padrão de pisada, somente um mínimo alinhamento do tornozelo apresentou diferença. Entretanto, esse mínimo alinhamento foi considerado insubstancial pelos pesquisadores. Ademais, os autores atribuem esses resultados à fadiga do sistema cardiovascular, ocorrendo antes que a resposta neuromuscular seja comprometida (ABT et al., 2011). Sendo assim, assumindo a ideia de que a fadiga pode contribuir como fator para alterações na cinemática da corrida que podem aumentar o risco de lesões musculoesqueléticas e/ou redução da performance, como dito por Kellis e Liassou, (2009). Esse estudo ainda reforça a necessidade de pesquisas que utilizem a cinemática 3D, pois resultados diferentes e extremamente relevantes podem ser encontrados em análises com maior grau de liberdade e, por isso, análises tridimensionais são importantes.

Suportando ainda mais os achados apresentados acima, García-Pinillos et al., (2016) não encontraram alterações cinemáticas durante dois protocolo de HIIT ( 10 x 400 m ou $40 \times 100 \mathrm{~m}$ ), investigando as variáveis angulares (tornozelo, joelho e quadril), parâmetros espaço-temporais (comprimento do passo, tempo de contato e de voo) e padrão de pisada. Os resultados mostram que o protocolo de 40 x 100 m provocou redução do tempo de contato e voo, aumentando o comprimento de passo. Alterações angulares nos membros inferiores também foram observadas: i) maior flexão de quadril e extensão de tornozelo no contato inicial; ii) pequena flexão do tornozelo e do joelho durante o movimento; iii) maior extensão de quadril na retirada do pé, quando comparados o primeiro de cada protocolo. Em contrapartida, não foram encontradas alterações do padrão de pisada em nenhuma comparação, nem entre o primeiro e último sprint dos protocolos ou os primeiros sprints entre os dois protocolos de HIIT. Apesar das alterações encontradas, os pesquisadores concluíram que não foram perturbações consistentes que poderiam gerar prejuízos físicos ou de performance.

E por fim, o último trabalho apresentado na revisão, dos mesmos autores anteriores, Garcia-Pinillos, Soto-Hermoso e Latorre-Roman, (2016) verificaram se um protocolo de HIIT (3 séries, com 4 corridas de 400 m, na maior velocidade possível, com 1 minuto de descanso entre as corridas), modificaria a biomecânica de atletas de endurance de acordo com seu estado de treinamento (grupo mais rápidos vs grupo menos rápidos) e nível de exaustão (grupo exausto vs grupo não exausto) durante o exercício. Os autores encontraram alterações somente na comparação entre os grupos. Foi encontrado maior comprimento de passo do grupo mais rápido e maior tempo de contato do grupo mais 
exausto. No primeiro sprint, o ângulo do joelho durante o movimento e na retirada do pé, assim como o ângulo do tornozelo, foram maiores no grupo menos rápidos. Diferenças também foram encontradas entre os grupos de maior e menor velocidade nos ângulos de quadril (redução para os mais rápidos e aumento para os menos rápidos) e joelho (aumento para os mais rápidos e redução para os menos rápidos) no momento da retirada do pé.

Para os grupos baseados na exaustão alcançada, também foram encontradas diferenças nos ângulos de quadril e joelho na retirada do pé, aumento e redução, respectivamente, ao fim do protocolo. Por fim, o padrão de pisada não sofreu alteração com esse modelo de HIIT. Novamente, embora algumas diferenças entre os grupos tenham sido encontradas, nem o estado de treinamento ou o nível de exaustão mostrouse consistente o bastante para causar alterações significativas na cinemática durante este protocolo de HIIT. Como o estudo anterior, a justificativa é o não estado de exaustão dos voluntários, o qual pode contribuir para possíveis alterações na mecânica da corrida.

Percebe-se também que a maioria dos trabalhos citados utilizaram voluntários treinados ou com alto nível de condicionamento físico para realização do HIIT, deixando uma lacuna para o público recreacional e/ou com baixa aptidão cardiorrespiratória. Outro ponto a ser destacado é que todos utilizaram a análise 2D, deixando uma grande lacuna sobre como as articulações se comportam nos outros planos do movimento, e as implicações dessas possíveis alterações.

Portanto, baseado em pesquisas anteriores, e buscando compreender a real influência da exaustão durante o exercício, o presente estudo é baseado na hipótese que uma sessão de HIIT até a exaustão voluntária modificará as articulações do tornozelo, joelho e quadril nos seus três planos de movimento, podendo trazer prejuízos físicos e de performance.

\section{OBJETIVO}

Analisar e comparar os efeitos de uma sessão aguda de HIIT sobre parâmetros cinemáticos das articulações dos membros inferiores em praticantes recreacionais de exercício físico, quando comparados o primeiro e último sprint. 


\section{PROCEDIMENTOS METODOLÓGICOS}

\subsection{Participantes}

O número amostral foi calculado com base nas variáveis centrais (i.e., valores angulares de quadril, joelho e tornozelo) apresentadas no estudo de García-Pinillos et al., (2019). Para tal, foi utilizado o software G*Power 3.1.9.2 - Dusseldorf, Germany (i.e., poder estatístico de 0,95, com alfa de $5 \%$ e um Effect size $f$ de 0,25). Sendo assim, os dados foram coletados de uma amostra de 18 voluntários universitários, praticantes recreacionais de exercício físico com frequência semanal de, no máximo, três vezes por semana há mais de três meses. Os procedimentos experimentais foram executados dentro das normas éticas previstas na Resolução 466/12, do Conselho Nacional de Saúde de 12/12/2012 (BRASIL, 2012) e da Resolução de Helsinki, (2001). O projeto foi aprovado pelo Comitê de Ética em Pesquisa da Escola de Educação Física e Esporte de Ribeirão Preto (n. do parecer: 2.311.522; CAAE: 70232317.2.0000.5659) (ANEXO A). Todos os participantes assinaram o Termo de Consentimento Livre e Esclarecido para participar da pesquisa, contendo: objetivo do estudo, procedimentos de avaliações e caráter de voluntariedade da participação do sujeito (Apêndice A).

\subsection{Procedimentos experimentais}

Todo o estudo foi realizado no Laboratório de Biomecânica e Controle Motor da Escola de Educação Física e Esporte de Ribeirão Preto (EEFERP-USP/RP). Foram realizadas duas sessões experimentais, com intervalo de 48 horas entre as mesmas. No primeiro dia de testes, os valores antropométricos e a velocidade pico em esteira foram quantificados. Na segunda sessão, os voluntários realizaram um protocolo de HIIT até a exaustão voluntária, para a obtenção das variáveis cinemáticas dos membros inferiores.

\subsection{Determinação da velocidade pico em esteira}

A velocidade pico em esteira (VPE) foi determinada por meio de um protocolo incremental, em esteira rolante (Inbrasport Millennium ATL ${ }^{\circledR}$, Porto Alegre, Brasil) até a exaustão voluntária. $\mathrm{O}$ protocolo consistiu em um aquecimento de cinco minutos a uma velocidade de $8 \mathrm{~km} \cdot \mathrm{h}^{-1}$. Em seguida (sem pausa), iniciava o protocolo incremental, com incrementos de $1 \mathrm{~km} \cdot \mathrm{h}^{-1}$ a cada três minutos de corrida, com inclinação constante de $1 \%$. O protocolo era interrompido pela inabilidade do participante de continuar o exercício e/ou exaustão voluntária (PIERCE et al., 1999). 


\subsection{Protocolo de Treinamento Intervalado de Alta Intensidade}

Após obtenção da VPE pelo teste de esforço, foi determinada a intensidade do HIIT, sendo $120 \%$ da VPE. A velocidade média dos participantes foi de $16,7 \pm 3,4 \mathrm{~km} \cdot \mathrm{h}^{-}$

${ }^{1} \mathrm{k}$. Antes do protocolo era realizado um aquecimento de cinco minutos em esteira rolante a uma velocidade de $8 \mathrm{~km} \cdot \mathrm{h}^{-1}$. O protocolo escolhido consistiu em realizar o máximo de esforços até a exaustão voluntária, com estímulo: recuperação de 30s:15s, sendo a recuperação em modo passivo, esse modelo de protocolo foi baseado no HIIT curto (BUCHHEIT; LAURSEN, 2013a) (Figura 2). Todos os voluntários, ao final do protocolo, reportaram o valor máximo da Percepção Subjetiva de Esforço (PSE), baseada na escala de Borg modificada (BORG, 1998) (Tabela 2).

Figura 3. Aquecimento (A), realização do esforço do protocolo HIIT (B), recuperação passiva do protocolo HIIT (C).
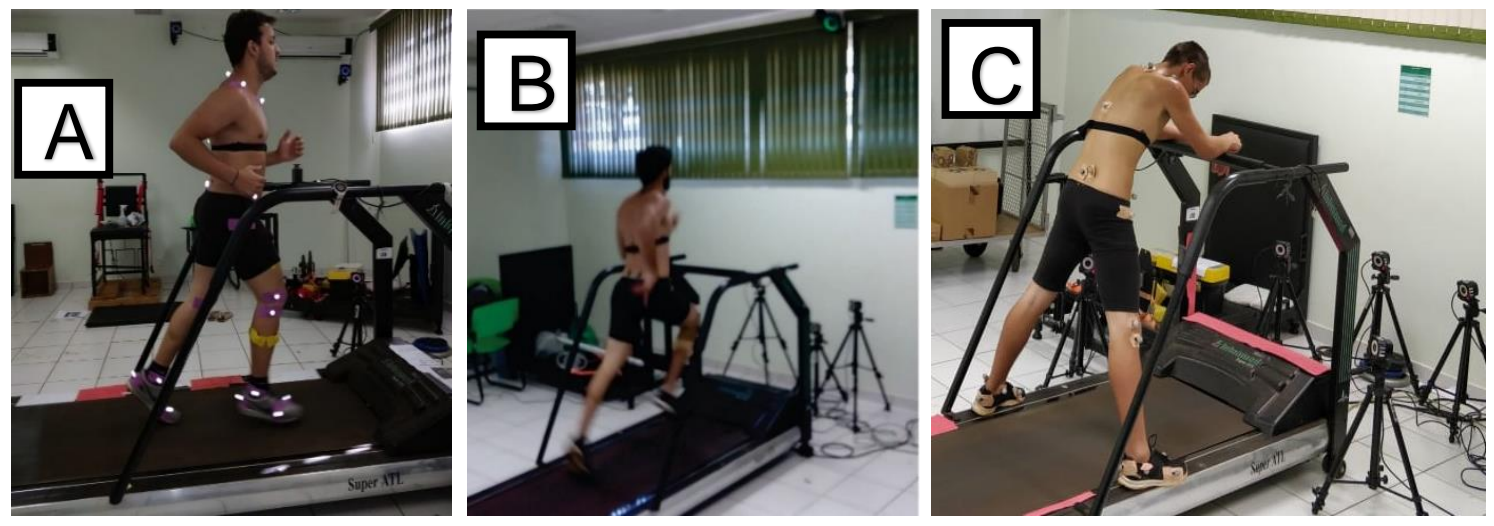

Tabela 2. Média e desvio padrão da PSE dos voluntários, no primeiro e último sprint

\begin{tabular}{ccc}
\hline \multicolumn{3}{c}{ Monitoramento do estado de exaustão voluntária } \\
\hline & 10 Sprint & Último Sprint \\
\cline { 2 - 3 } PSE & 3 & 10 \\
\hline
\end{tabular}

PSE = Percepção subjetiva de esforço.

\subsection{Aquisição dos dados}

Para obtenção das variáveis cinemáticas, foi utilizado um sistema de análise de movimento tridimensional, constituído por 13 câmeras de vídeo infravermelho OptiTrack $^{T M}$ (Natural Point Inc. - USA) operando na frequência de $250 \mathrm{~Hz}$ com o 
software Motive ${ }^{\circledR}$. Foram fixados 27 marcadores anatômicos $(10 \mathrm{~mm}$ de raio) posicionados em diferentes pontos corporais. Os marcadores foram posicionados nos seguintes acidentes ósseos: 1 e 2) acrômio direito e esquerdo; 3 ) esterno; 4 e 5) processo espinhoso das vertebras C7 e T10; 6 e 7) crista ilíaca anterossuperior direita e esquerda; 8 e 9) crista ilíaca póstero superior direita e esquerda; 10 e 11) trocânter maior do fêmur direito e esquerdo; 12 e 13) epicôndilo lateral direito e esquerdo; 14 e 15) epicôndilo medial direito e esquerdo; 16 e 17) cabeça da fíbula direita e esquerda; 18 e 19) maléolo lateral direito e esquerdo; 20 e 21) maléolo medial direito e esquerdo; 22 e 23) cabeça do quinto metatarso direito e esquerdo; 24 e 25) cabeça do primeiro metatarso direito e esquerdo; 26 e 27) tuberosidade do calcâneo direito e esquerdo (Figura 3). Antes de iniciar o teste, uma tomada estática de $10 \mathrm{~s}$ dos participantes foi realizada para que seja possível encontrar os valores angulares anatômicos de referência para a realização dos cálculos para encontrar as angulações articulares.

Figura 4. Marcadores utilizados no momento da coleta (A e B) e reconstrução 3D realiza no software Motive (C).
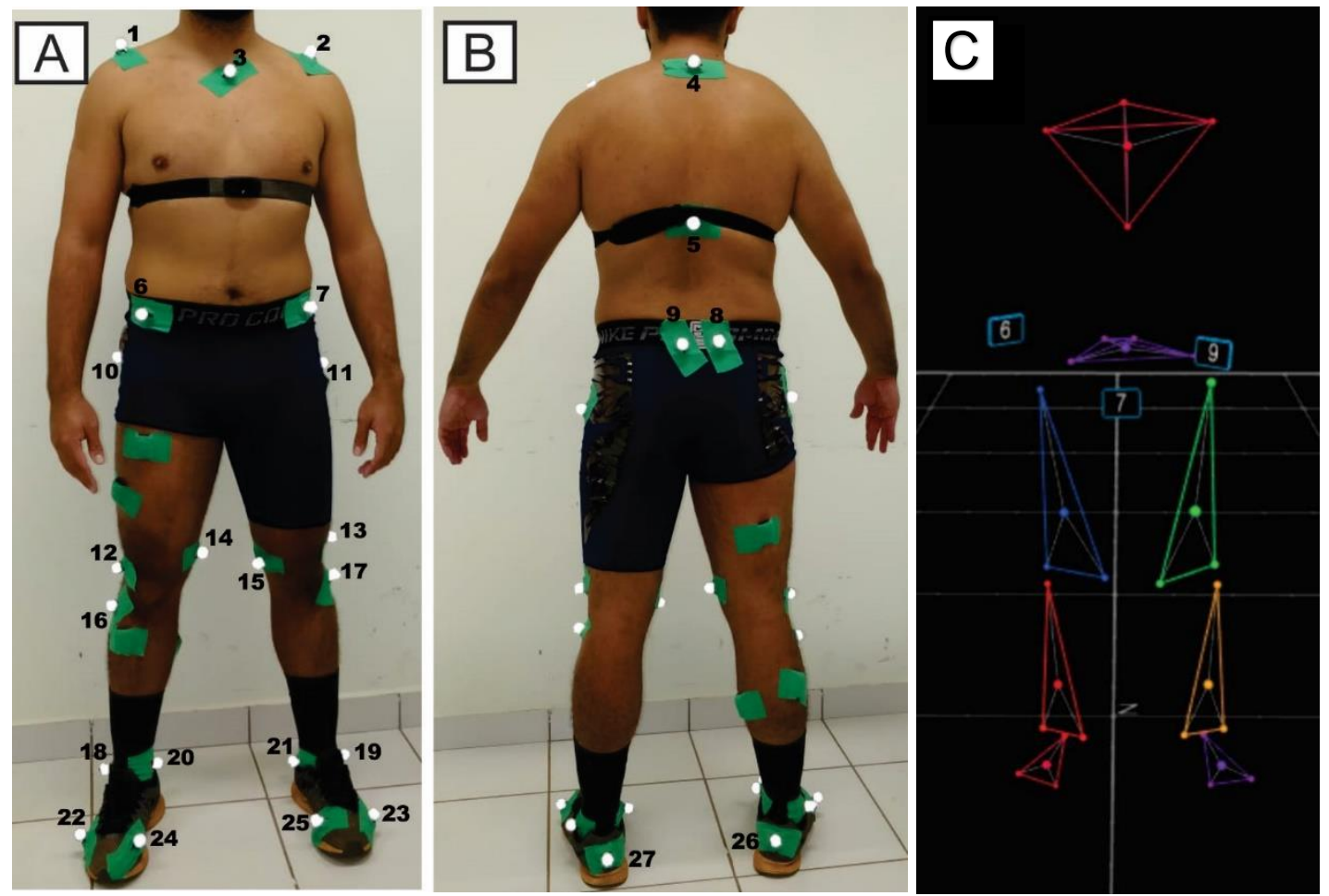

\subsection{Processamento dos dados}

Os marcadores foram categorizados e suas trajetórias foram reconstruídas, no mesmo software da aquisição e todos os gaps (situações em que o marcador não é visível por minimamente duas câmeras) foram preenchidos respeitando a trajetória de cada 
marcador. Após isso, os arquivos foram exportados em .c3d e no software Visual3D ${ }^{\circledR}$, em rotinas pré definidas, os dados cinemáticos foram suavizados por um filtro Butterworth digital de $4^{\mathrm{a}}$ ordem com frequência de corte de $10 \mathrm{~Hz}$ obtida pela análise de resíduos (WINTER, 2009), tal análise foi realizada em ambiente Matlab ${ }^{\circledR}$.

Posteriormente, os sistemas de referências dos membros inferiores foram definidos por $x, y$ e $z$ construídos pelas coordenadas tridimensionais de cada marcador. Para o sistema da pelve, marcadores das proeminências ósseas na crista ilíaca anterossuperior direita e esquerda e na crista ilíaca póstero superior direita e esquerda foram usadas. Para o sistema da coxa, marcadores no trocânter maior do fêmur direito e esquerdo, epicôndilo lateral direito e esquerdo e epicôndilo medial direito e esquerdo foram utilizados. $\mathrm{O}$ sistema da perna foi definido pelos marcadores da cabeça da fíbula direita e esquerda, maléolo lateral direito e esquerdo e maléolo medial direito e esquerdo. Por fim, para o sistema do pé, os marcadores da tuberosidade do calcâneo direito e esquerdo, cabeça do primeiro metatarso direito e esquerdo e cabeça do quinto metatarso direito e esquerdo foram usados (Figura 4). Com os sistemas de referência definidos, foi possível realizar os cálculos para obter os ângulos de Euler com as matrizes de rotação (WU et al., 2002), os quais representam os movimentos rotacionais do quadril, joelho e tornozelo.

Figura 5. Representação dos sistemas da pelve, coxa, perna e pé.

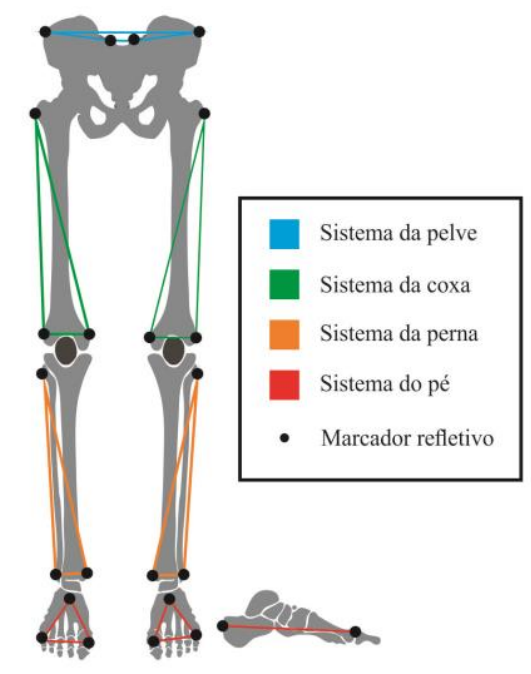

Para o cálculo dos valores angulares da articulação do quadril considerou-se a pelve como segmento fixo e a coxa como segmento móvel, assim as rotações foram realizadas entre o sistema móvel (coxa) em relação ao sistema fixo (pélvis). O mesmo aplicou-se para as demais articulações, sendo assim, a articulação do joelho considerou a 
coxa como segmento fixo e a perna como segmento móvel. E por fim, no tornozelo foi considerado a perna como segmento fixo e o pé como segmento móvel. Os ângulos foram calculados separadamente em cada plano e, para a representação dos graus negativos e positivos, o eixo y representa flexão e extensão, adução e abdução no eixo x, e rotação interna e externa no eixo z (Tabela 3 ).

Tabela 3. Movimentos angulares

\begin{tabular}{c|cc|cc|cc}
\hline & \multicolumn{5}{c}{ Movimentos Articulares } & \\
\hline $\begin{array}{c}\text { Tornozelo } \\
\text { Direito }\end{array}$ & Dorsiflexão (+) & Flex. Plantar (-) & Adução (-) & Abdução (+) & Rot. Interna (-) & Rot. Externa (+) \\
$\begin{array}{c}\text { Joelho } \\
\text { Direito }\end{array}$ & Flexão (-) & Extensão (+) & Adução (+) & Abdução (-) & Rot. Interna (-) & Rot. Externa (+) \\
$\begin{array}{c}\text { Quadril } \\
\text { Direito }\end{array}$ & Flexão (+) & Extensão (-) & Adução (-) & Abdução (+) & Rot. Interna (-) & Rot. Externa (+) \\
$\begin{array}{c}\text { Tornozelo } \\
\text { Esquerdo }\end{array}$ & Dorsiflexão (+) & Flex. Plantar (-) & Adução (+) & Abdução (-) & Rot. Interna (+) \\
$\begin{array}{c}\text { Joelho } \\
\text { Esquerdo }\end{array}$ & Flexão (-) & Extensão (+) & Adução (-) & Abdução (+) & Rot. Interna (+) \\
$\begin{array}{c}\text { Quadril } \\
\text { Esquerdo }\end{array}$ & Flexão (+) & Extensão (-) & Adução (+) & Abdução (-) & Rot. Interna (-) \\
\hline
\end{tabular}

Nota: Flex. = Flexão; Rot. = Rotação.

Todas as variáveis cinemáticas foram analisadas do instante $10 \mathrm{~s}$ aos $20 \mathrm{~s}$ dos sprints, para que não houvesse interferência do momento de entrada e saída da esteira. Tais variáveis foram obtidas por meio de rotina em ambiente Matlab ${ }^{\circledR}$. Por fim, a fase de suporte foi definida entre o primeiro e último contato do pé, encontradas pelo pico vertical da marcador refletivo do calcâneo durante a corrida. Os ângulos articulares foram normalizados em relação ao tempo (0-100\%).

\subsection{Análise Estatística}

Para comparar os efeitos do protocolo de HIIT até a exaustão voluntária, sobre as articulações do quadril, joelho e tornozelo, entre o primeiro e último sprint, as séries temporais dos ângulos normalizados foram analisadas pelo teste $\mathrm{t}$ de Student para amostras pareadas, calculadas pelo Statistical Parametric Mapping (SPM). Este método 
foi desenvolvido inicialmente para análises cerebrais (PENNY et al., 2011; ASHBURNER, 2012) permitindo a análise estatística de campos n-dimensionais delimitados e suavizados. Em sequência, Pataky, Robinson e Vanrenterghem, (2013), mostraram a eficácia do SPM na análise unidimensional de campos vetoriais, e já foi usado anteriormente em investigações biomecânicas usando comparações ponto a ponto, permitindo detectar onde na série temporal ocorre a diferença (PATAKY, 2010). Este procedimento foi realizando usando o software Matlab ${ }^{\circledR}$.

\section{RESULTADOS}

Ao final do protocolo, os participantes apresentaram maior flexão plantar no último sprint, quando comparado ao primeiro. Os resultados do SPM mostraram diferenças entre $0-3 \%$ do ciclo da corrida para o tornozelo direito $(\mathrm{p}=0,046)$ (Figura 6) e entre $0-2 \%$ para o tornozelo esquerdo $(\mathrm{p}=0,048)$ (Figura 7). Adicional a isso, durante o fim da fase de balanço, preparação para o passo seguinte, maior flexão plantar também foi observada ao final do último sprint, porém foi encontrada entre $94-100 \%$ e $92-100 \%$ do ciclo da corrida de ambos tornozelos, direito $(p=0,023)$ e esquerdo $(p=0,014)$, respectivamente.

Figura 6. Resultado dos ângulos do tornozelo direito

\section{Tornozelo Direito}
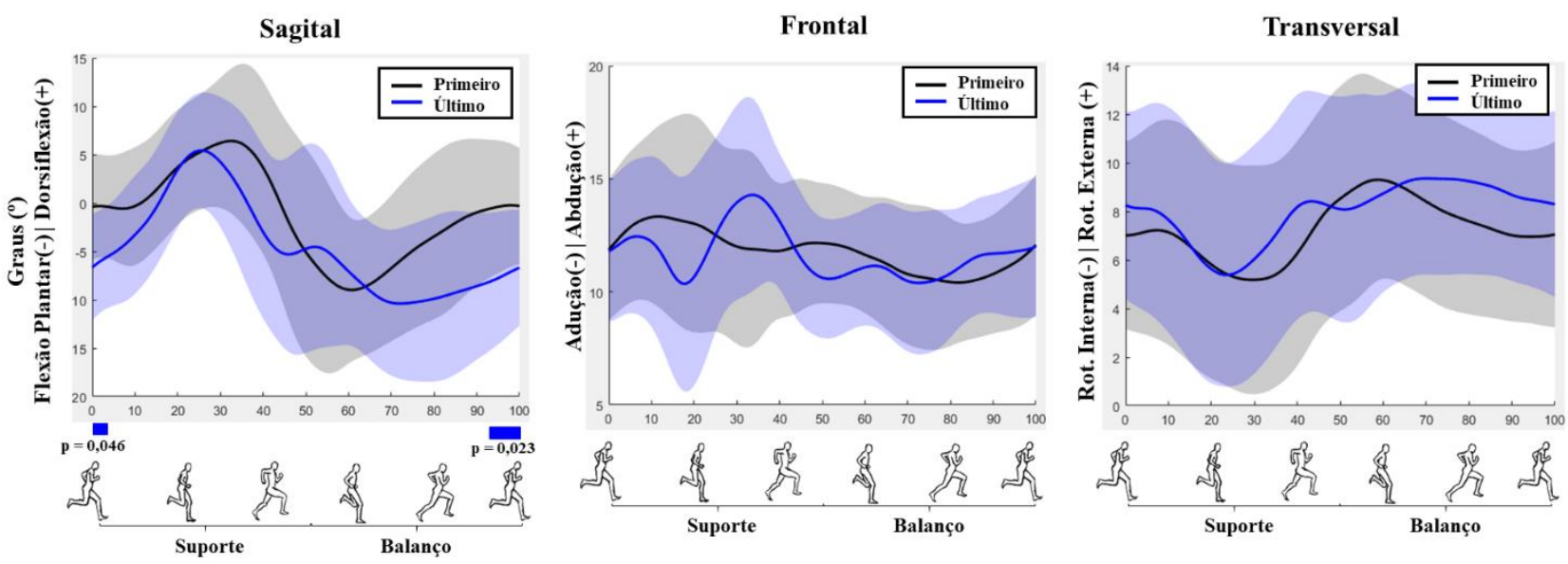

Rot. = Rotação; As barras na parte inferior da figura representam a fase do ciclo da corrida onde as diferenças significativas entre o primeiro e o último sprint foram encontradas. 
Figura 7. Resultado dos ângulos do tornozelo esquerdo

\section{Tornozelo Esquerdo}
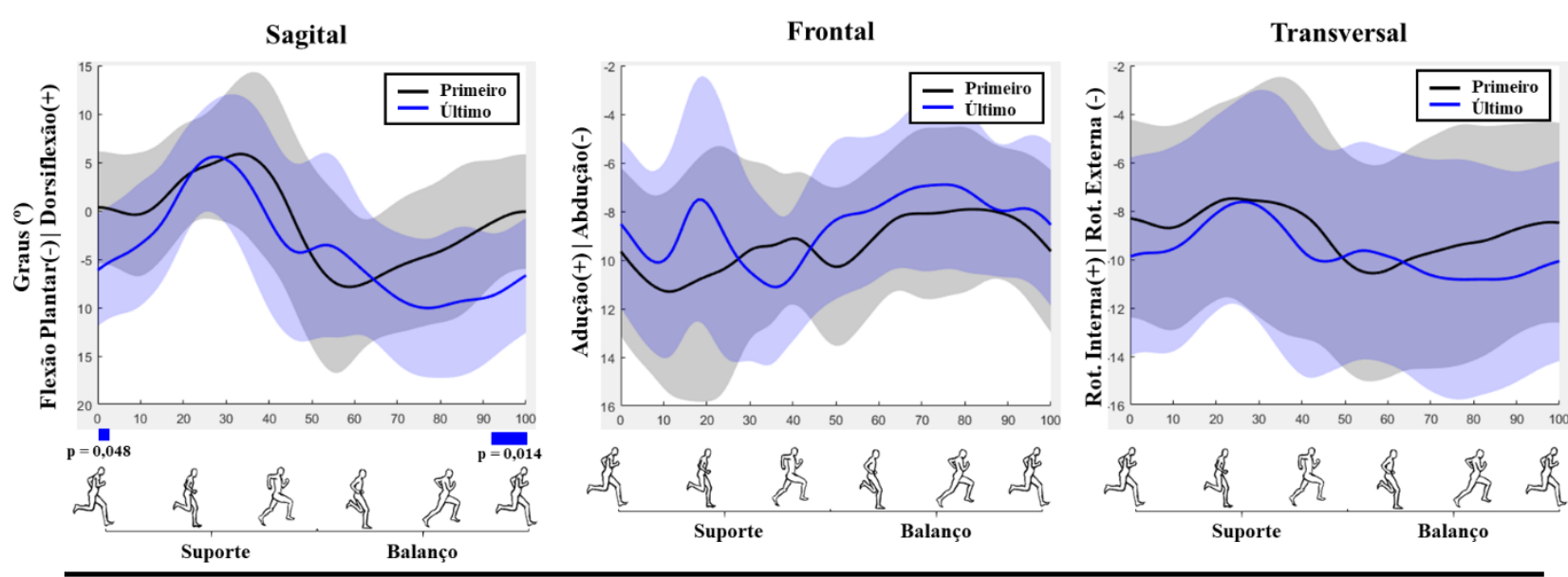

Rot. = Rotação; As barras na parte inferior da figura representam a fase do ciclo da corrida onde as diferenças significativas entre o primeiro e o último sprint foram encontradas.

Para a articulação do joelho direito (Figura 8) e esquerdo (Figura 9), nenhuma diferença foi encontrada em nenhum dos planos, ao final do protocolo.

Figura 8. Resultado dos ângulos do joelho direito

\section{Joelho Direito}
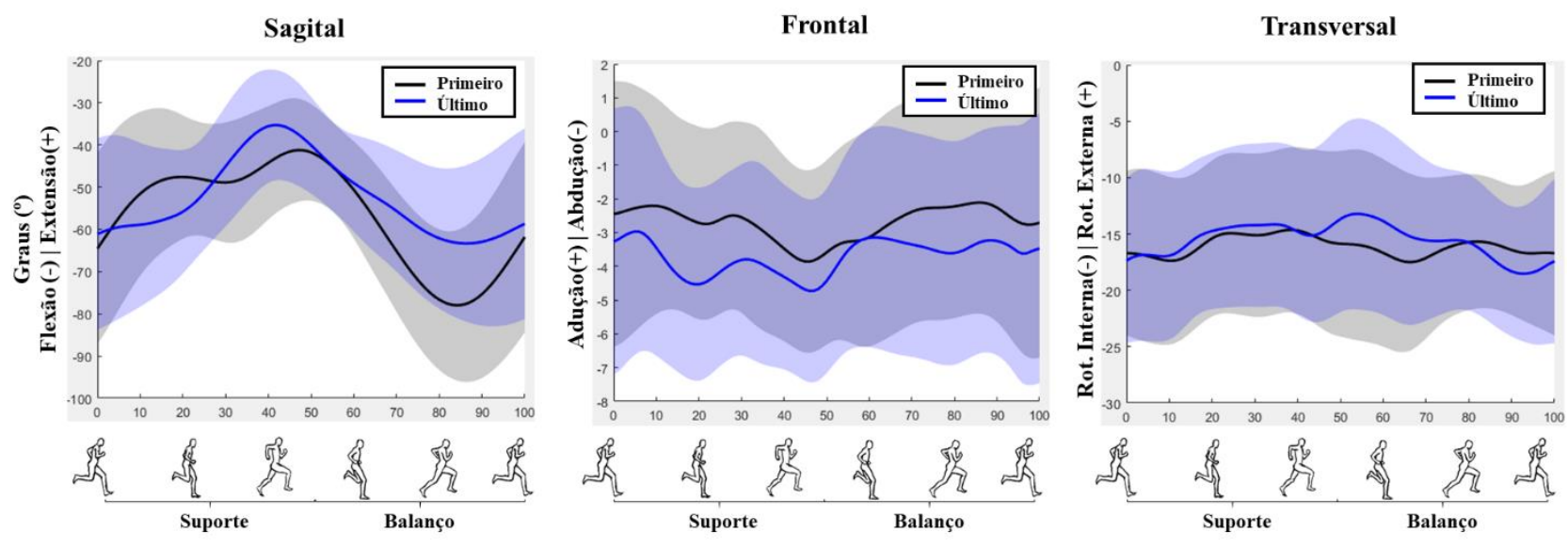

Rot. $=$ Rotação; 
Figura 9. Resultado dos ângulos do joelho esquerdo

\section{Joelho Esquerdo}
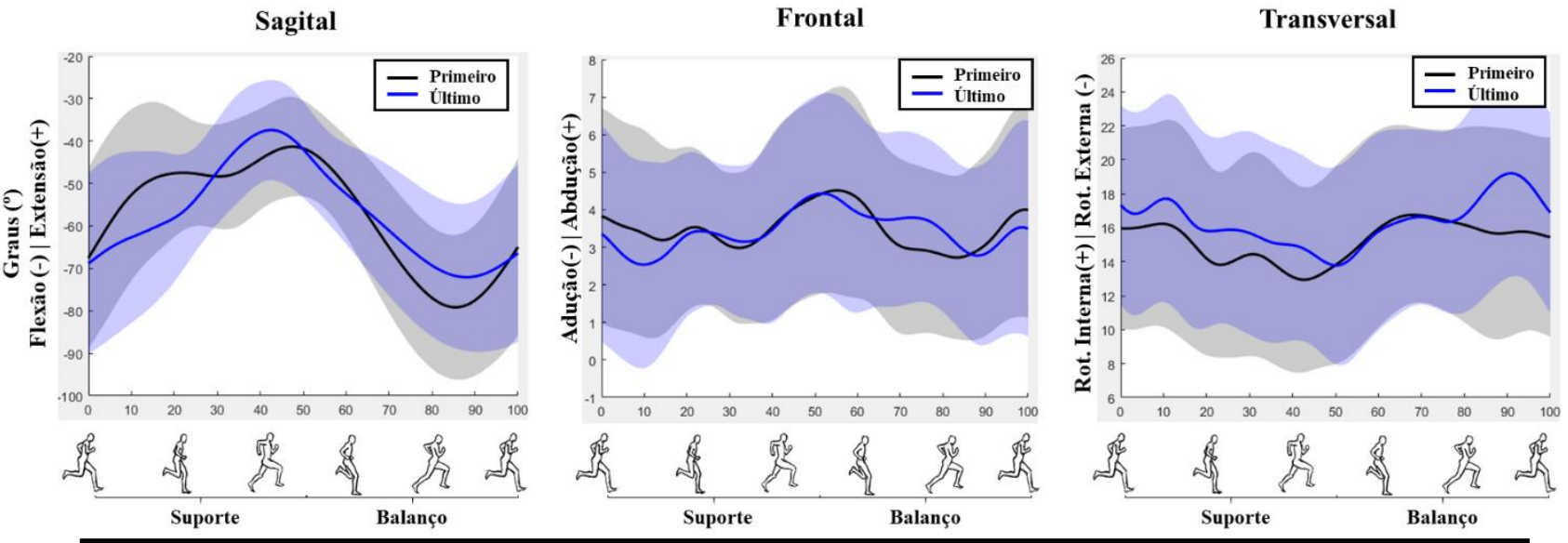

Rot. = Rotação;

Tal comportamento, também foi observado na articulação do quadril, direito (Figura 10) e esquerdo (Figura 11), ao final do protocolo.

Figura 10. Resultado dos ângulos do quadril direito

\section{Quadril Direito}
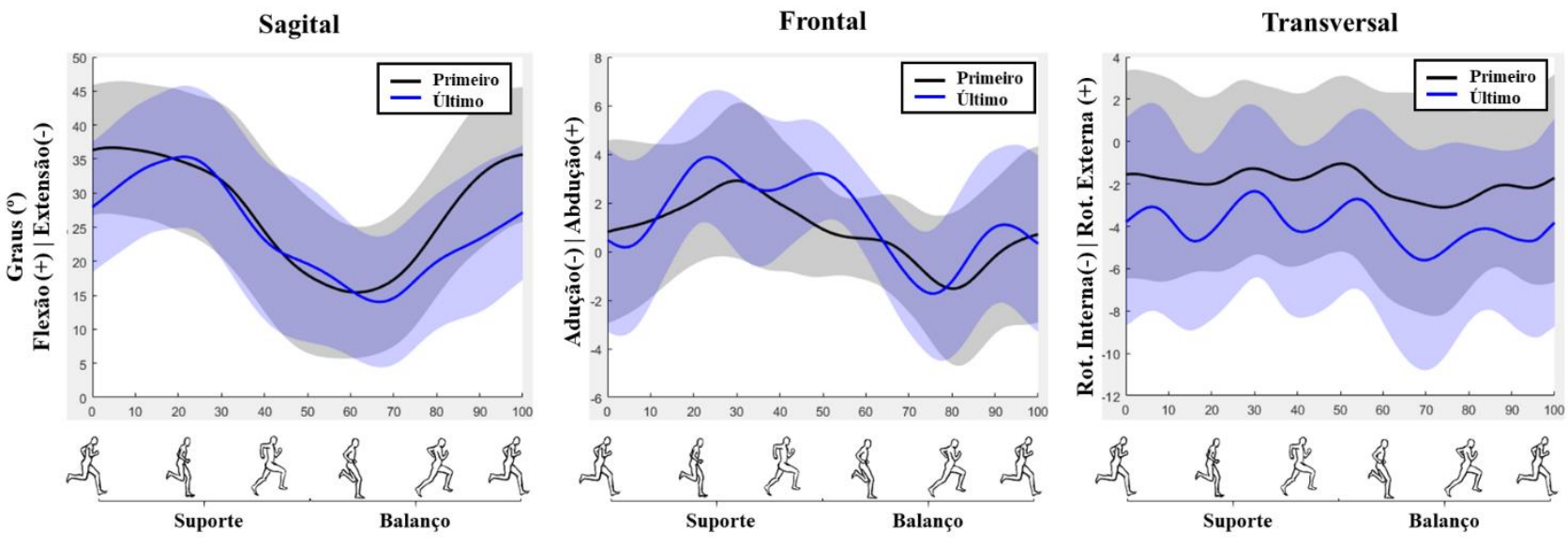

Rot. = Rotação; 
Figura 11. Resultado dos ângulos do quadril esquerdo

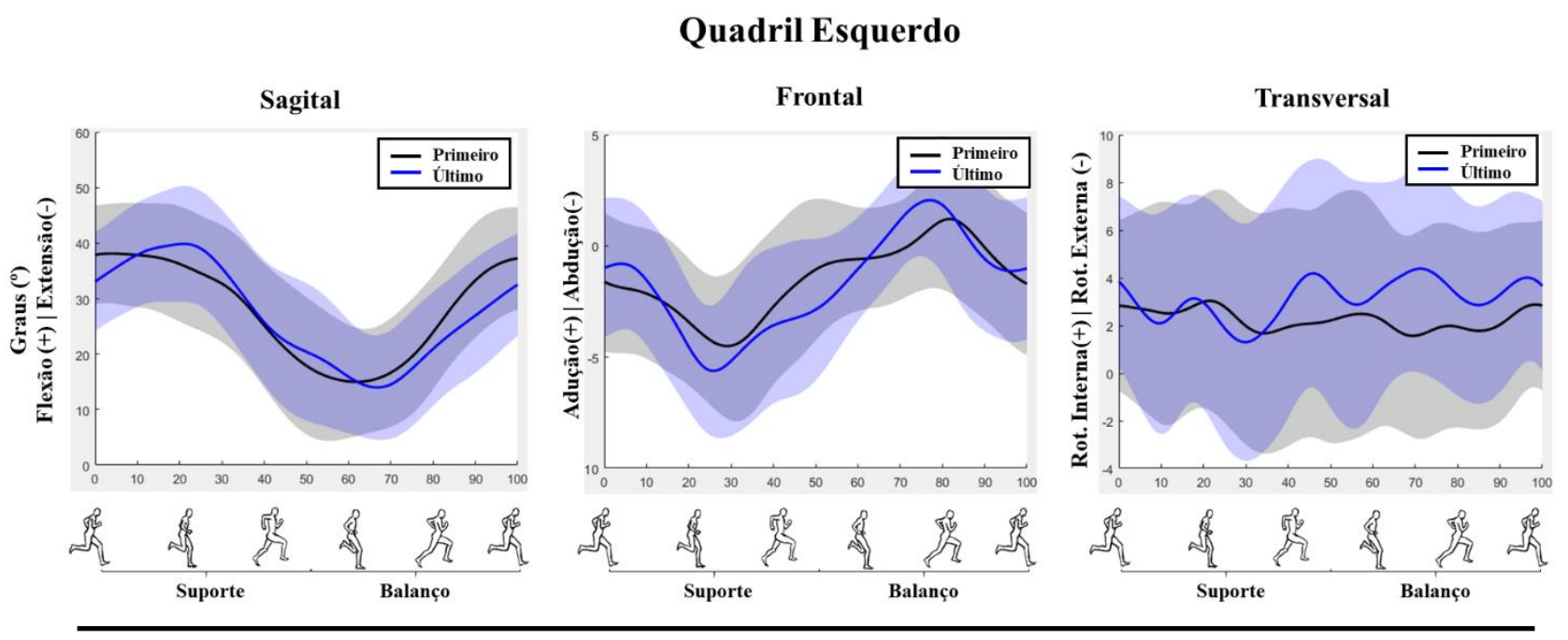

Rot. $=$ Rotação;

\section{DISCUSSÃO}

O presente estudo buscou analisar os efeitos de uma sessão aguda de HIIT sobre parâmetros cinemáticos dos membros inferiores em praticantes recreacionais de exercício físico. Após os testes, a hipótese inicial não foi confirmada, visto as alterações encontradas somente nas articulações dos tornozelos.

Os principais achados se baseiam nas alterações da articulação do tornozelo direito e esquerdo, no plano sagital. Os resultados encontrados nos indicam que a exaustão dos participantes pode ser a principal relação para tais alterações.

Corroborando com os resultados encontrados, Koblbauer et al., (2014) investigou o efeito da exaustão em alterações cinemáticas observadas durante uma corrida. Além disso, também tinha como objetivo relacionar tais alterações com a resistência dos músculos do Core. Os resultados evidenciaram que, quando comparado o início do protocolo (sem exaustão) com o final (com exaustão), houve aumento do pico médio de flexão do tronco e redução da extensão do tronco. Aumento significante também foi encontrado na eversão do tornozelo não dominante. Nenhuma outra alteração foi encontrando para os outros movimentos das articulações. Em relação ao Core, foi encontrado uma relação considerável entre o aumento da flexão do tronco com a resistência dos músculos extensores da coluna, somente. Os autores discutem que a alteração do tronco pode estar relacionada com a exaustão local do músculo paraespinhal, podendo apresentar aumento do ângulo de flexão durante uma corrida. Eles dizem que 
essa exaustão local pode resultar diretamente na redução da habilidade em manter uma boa postura durante esse tipo de exercício. Para os autores, o aumento da eversão do tornozelo também está relacionado com a exaustão muscular local, e apesar da sutil alteração encontrada, o efeito acumulativo durante uma corrida pode ser considerada como uma contribuição para fatores lesivos. A presente pesquisa corrobora com os achados do estudo citado acima, visto que também foram encontradas alterações nos ângulos dos tornozelos.

Outros estudos também encontraram alterações na cinemática em corrida contínua, como os autores supracitados, quando os voluntários foram expostos a exercícios que induziam à exaustão, mostrando interação substancial entre exaustão e alterações cinemáticas. (MIZRAHI et al., 2000; DERRICK; DEREU; MCLEAN, 2002; DIERKS; DAVIS; HAMILL, 2010). Em contrapartida, alguns estudos não encontraram alterações biomecânicas durante a execução de diferentes exercícios de corrida (COLLINS et al., 2000; GARCÍA-PINILLOS et al., 2016). Por exemplo, Abt et al., (2011) investigaram se uma sequência de corridas exaustivas acarretaria em mudanças na cinemática, nas acelerações dos impactos da perna e da cabeça e na capacidade de atenuar esses impactos. Em seus resultados, os autores evidenciaram que nenhuma das variáveis apresentaram diferenças antes ou depois da corrida até a exaustão. Os pesquisadores justificaram seus resultados, pautados na possibilidade do alto estresse cardiovascular ter ocorrido antes da exaustão no sistema neuromuscular, fazendo com que os voluntários parassem antes de presentarem alterações das variáveis investigadas. Agregado a isso, eles apontam que o baixo volume do protocolo também pode contribuir para a não modificação da cinemática, das acelerações dos impactos e na capacidade de atenuar esses impactos. Tal afirmação pode se tornar inconclusiva, visto que o presente estudo, utilizou um protocolo de baixo volume, porém, com alta intensidade, e encontrou diferenças na cinemática dos praticantes, apesar da diferença entre os protocolos. Tais inconsistências na literatura evidencia a importância de analisarmos as diversas variáveis que influenciam a biomecânica da corrida, todos os seus planos e eixos, em diferentes modalidades, nesta presente pesquisa, o HIIT curto em esteira.

Buscando esse entendimento sobre as alterações causadas pela exaustão durante o exercício, Kellis e Liassou, (2009), mostraram que a exaustão tem sido hipotetizada na alteração biomecânica e na função neuromuscular de maneira que possibilitaria conduzir à riscos lesivos e/ou perda de performance. A tentativa de manter o exercício em estado de exaustão mostrou aumento da tensão, cisalhamento e forças de impacto nos membros 
inferiores (MIZRAHI et al., 2000; DERRICK; DEREU; MCLEAN, 2002). Devido à exaustão, os tempos de reação dos músculos em seus ciclos de contração (fase excêntrica e concêntrica) ficam comprometidos, reduzindo a transferência de energia para a execução do movimento (MIZRAHI et al., 2000).

Sendo assim, os resultados do presente estudos podem estar relacionados com o efeito da exaustão durante o protocolo, tanto exaustão cardiovascular quanto neuromuscular. Somado a isso, a exaustão, além de alterar a cinemática na corrida, afeta diretamente o sistema proprioceptivo, podendo resultar em uma resposta demorada em sua ativação muscular, principalmente para a articulação do joelho, possibilitando cenário para risco lesivo. Entretanto, as modificações encontradas pelo presente estudo não causam grande preocupação, visto que essas alterações podem ser decorrentes à ajustes mecânicos atrelados ao estado de exaustão, similar ao encontrado no trabalho de García-Pinillos et al., (2016).

Um ponto a ser destacado que limita as comparações, são os diferentes protocolos para a análise da biomecânica da corrida, impossibilitando uma análise mais fidedigna dos resultados. No entanto, alguns autores direcionaram seus trabalhos utilizando protocolos de HIIT para verificar mudanças cinemáticas (COLLINS et al., 2000; LATORRE-ROMÁN et al., 2015; GARCIA-PINILLOS; SOTO-HERMOSO; LATORRE-ROMAN, 2016; GARCÍA-PINILLOS et al., 2019), na tentativa de aproximar ao máximo os parâmetros comparativos entre os tipos de HIIT, seja ela longo, curto, Repeated Sprint Training (RST) ou Sprint Interval Training (SIT) (BUCHHEIT; LAURSEN, 2013a).

A presente pesquisa foi a primeira a comparar se a quantidade de sprints influenciaria na biomecânica de corrida quando praticantes recreacionais de atividade física fizessem um protocolo de HIIT de forma aguda, até a exaustão voluntária. Um único trabalho que chegou próximo a isso foi o de Garcia-Pinillos, Soto-Hermoso e Latorre-Roman, (2016), que separaram suas análises em voluntários mais rápidos e mais lentos e voluntários que chegaram até a exaustão ao fim do protocolo e os que não chegaram.

Os achados do presente estudo apontaram que os participantes alteraram somente os ângulos de ambos os tornozelos no plano sagital. Tais alterações corroboram com os estudos de Garcia-Pinillos, Soto-Hermoso e Latorre-Roman, (2016), que encontraram aumento da angulação de tornozelo no grupo mais rápido e no grupo que chegou a exaustão durante a atividade. Resultados similares ao da presente pesquisa.

Portanto, o protocolo de HIIT proposto pelo estudo, para praticantes recreacionais, pode 
alterar sua mecânica de corrida, caso seja levado até a exaustão, porém, sem causar grandes riscos à saúde. Diversos aspectos precisam ser controlados para que a prescrição desse tipo de exercício seja o menos prejudicial possível, tais como, aptidão cardiorrespiratória, lesões existentes, desvios posturais e aumento excessivo do volume e da intensidade do treino, por exemplo.

\section{LIMITAÇÕES DO ESTUDO}

O presente estudo investigou apenas variáveis cinemáticas. Futuras investigações devem incluir análises dinâmicas e eletromiográficas para quantificar as cargas articulares e o padrão de ativação muscular durante um protocolo de HIIT em esteira. Adicional a isso, comparar os outros modelos de HIIT, não somente o curto, também mostra-se necessário.

\section{CONCLUSÃO}

O presente estudo evidenciou que um protocolo de HIIT curto tem pouca influência para alterar a cinemática dos membros inferiores dos praticantes. Apesar de ter encontrado diferença, no plano sagital, em ambos tornozelos, esse tipo de exercício parece não causar maiores efeitos na mecânica de corrida. Tais diferenças podem estar relacionadas com ajustes mecânicos causados pelo estado de exaustão do grupo investigado. Portanto, os achados da presente pesquisa mostraram que realizar um protocolo de HIIT curto até a exaustão voluntária, de modo geral, não altera a cinemática dos membros inferiores, em praticantes recreacionais de exercício físico. 


\section{REFERÊNCIAS BIBLIOGRÁFICAS}

ABT, J. P. et al. Running kinematics and shock absorption do not change after brief exhaustive running. Journal of Strength and Conditioning Research, v. 25, n. 6, p. 1479-1485, 2011.

ASHBURNER, J. SPM: A History. NeuroImage, v. 62, n. 2, p. 791-800, ago. 2012.

ASSOCIATION, W. M. World Medical Association Declaration of Helsinki. Ethical principles for medical research involving human subjects. Bulletin of the World Health Organization, v. 79, n. 4, p. 373, 2001.

BILLAT, L. V. Interval Training for Performance : A Scientific and Empirical Practice Special Recommendations for Middle- and Long-Distance Running . Part II : Anaerobic Interval Training. Sports Medicine, v. 31, n. 2, p. 75-90, 2001 a.

BILLAT, L. V. Interval Training for Performance : A Scientific and Empirical Practice Special Recommendations for Middle- and Long-Distance Running . Part I : Aerobic Interval Training. Sports Medicine, v. 31, n. 1, p. 13-31, 2001 b.

BORG, G. Borg's Perceived Exertion And Pain Scales. [s.l: s.n.]

BROOKS, D. S. Program design for personal trainers. [s.l.] IDEA Personal Trainer, 2000.

BUCHHEIT, M.; LAURSEN, P. B. High-Intensity Interval Training, Solutions to the Programming Puzzle Part I : Cardiopulmonary Emphasis. Sports Medicine, n. Março, 2013a.

BUCHHEIT, M.; LAURSEN, P. B. High-Intensity Interval Training, Solutions to the Programming Puzzle. Part II: Anaerobic Energy, Neuromuscular Load and Practical Applications. Sports Medicine, n. Julho, 2013b.

COLLINS, M. H. et al. Acute Effects of Intense Interval Training on Running Mechanics. Journal of sports sciences, v. 18, n. 2, p. 83-90, fev. 2000.

Conselho Nacional de Saúde. Disponível em: <http://conselho.saude.gov.br/resolucoes/reso_96.htm>. Acesso em: 20 jul. 2016.

CUNNINGHAM, D. A.; MCCRIMMON, D.; VLACH, L. F. Cardiovascular Response to Interval and Continuous Training in Women. European Journal of Applied Physiology, v. 197, n. 263, p. 187-197, 1979.

DARLING, J. .; LINDERMAN, J. .; LAUBACH, L. . Energy expenditure of continuous and intermittent exercise in college-aged males. Journal of Exercise Physiology, v. 4, n. 8 , p. $1-8,2005$.

DERRICK, T. R.; DEREU, D.; MCLEAN, S. P. Impacts and kinematic adjustments during an exhaustive run. Medicine \& Science in Sports \& Exercise, n. 2016, 2002. 
DIERKS, T. A.; DAVIS, I. S.; HAMILL, J. The Effects of Running in an Exerted State on Lower Extremity Kinematics and Joint Timing. Journal of biomechanics, v. 43, n. 15, p. 2993-2998, nov. 2010.

ESFARJANI, F.; LAURSEN, P. B. Manipulating high-intensity interval training: effects on, the lactate threshold and $3000 \mathrm{~m}$ running performance in moderately trained males. Journal of Science and Medicine in Sport, v. 10, p. 27-35, 2007.

FERNANDEZ, A. . et al. Influência do treinamento aeróbio e anaeróbio na massa de gordura corporal de adolescentes obesos. Revista Brasileira de Medicina do Esporte, v. 10, n. 3, p. 152-158, 2004.

FOX, E. .; BOWERS, R. ; MERLE, L. . Bases Fisiológicas da Educação Física e dos Desportos. $4^{\text {a }}$ ed. Rio de Janeiro: Guanabara Koogan, 1992.

GALlO, R. A.; PLAKKE, M.; SILVIS, M. L. Common leg injuries of long-distance runners: anatomical and biomechanical approach. Sports health, v. 4, n. 6, p. 485-495, 2012.

GARCÍA-PINILLOS, F. et al. Kinematic alterations after two high-intensity intermittent training protocols in endurance runners. Journal of Sport and Health Science, 2016.

GARCIA-PINILLOS, F.; SOTO-HERMOSO, V. M.; LATORRE-ROMAN, P. A. Do Running Kinematic Characteristics Change over a Typical HIIT for Endurance Runners? Journal of strength and conditioning research, v. 30, n. 10, p. 2907-2917, out. 2016.

GIBALA, M. J. et al. Physiological adaptations to low-volume, high-intensity interval training in health and disease. The Journal Physiology, v. 5, p. 1077-1084, 2012.

GIRARD, O. et al. Mechanical alterations during interval-training treadmill runs in highlevel male team-sport players. Journal of Science and Medicine in Sport, v. 20, n. 1, p. 87-91, 2017.

GIST, N. H. et al. Sprint interval training effects on aerobic capacity: a systematic review and meta-analysis. Sports medicine, v. 44, n. 2, p. 269-279, 2014.

GONZALEZ-MOHINO, F. et al. Effects of Continuous and Interval Training on Running Economy, Maximal Aerobic Speed and Gait Kinematics in Recreational Runners. Journal of strength and conditioning research, v. 30, n. 4, p. 1059-1066, abr. 2016.

HANLEY, B.; MOHAN, A. K. Changes in Gait during Constant Pace Treadmill Running. Journal of strength and conditioning research, v. 28, n. 5, p. 1219-1225, maio 2014.

HANLEY, B.; SMITH, L. C.; BISSAS, A. Kinematic Variations Due to Changes in Pace during Men's and Women's $5 \mathrm{~km}$ Road Running. International Journal of Sports Science \& Coaching, v. 6, n. 2, p. 243-252, 1 jun. 2011. Disponível em: <https://doi.org/10.1260/1747-9541.6.2.243>.

HEYDARI, M. . et al. The effect of high intensity intermittent exercise on body 
composition of overweight young males. Journal of Obesity, 2012.

HRELJAC, A. Impact and Overuse Injuries in Runners. Medicine and science in sports and exercise, v. 36, n. 5, p. 845-849, maio 2004.

KEATING, S. E. . et al. Continuous exercise but not high intensity interval training improves fat distribution in overweight adults. Journal of Obesity, 2014.

KELLIS, E.; LIASSOU, C. The Effect of Selective Muscle Fatigue on Sagittal Lower Limb Kinematics and Muscle Activity during Level Running. The Journal of orthopaedic and sports physical therapy, v. 39, n. 3, p. 210-220, mar. 2009.

KOBLBAUER, I. F. et al. Kinematic Changes during Running-Induced Fatigue and Relations with Core Endurance in Novice Runners. Journal of science and medicine in sport, v. 17, n. 4, p. 419-424, jul. 2014.

LANFORGIA, J. et al. Comparison of energy expenditure elevations after submaximal and supramaximal running. Journal Applied of Physiology, v. 82, n. 2, p. 661-666, 1987.

LATORRE-ROMAN, P. A. et al. Acute Effects of High-Intensity Intermittent Training on Kinematics and Foot Strike Patterns in Endurance Runners. Journal of sports sciences, p. 1-8, ago. 2016.

LATORRE-ROMÁN, P. Á. et al. Acute effect of a long-distance road competition on foot strike patterns, inversion and kinematics parameters in endurance runners.

International Journal of Performance Analysis in Sport, v. 15, p. 588-597, 2015.

LITTLE, J. P. . et al. A practical model of low volume high-intensity interval training induces mithocondrial biogenesis in human skeletal muscle: potential mechanis. The Journal Physiology, v. 588, n. 6, p. 1011-1022, 2010.

MAAS, E. et al. Novice runners show greater changes in kinematics with fatigue compared with competitive runners. Sports Biomechanics, v. 17, p. 1-11, 21 jul. 2018.

MARCINKO, K. et al. High intensity interval training improves liver and adipose tissue insulin sensitivity. Molecular Metabolism, v. 4, n. 12, p. 903-915, 2015.

MILNER, C. E.; HAMILL, J.; DAVIS, I. Are knee mechanics during early stance related to tibial stress fracture in runners? Clinical Biomechanics, v. 22, n. 6, p. 697-703, 1 jul. 2007. Disponível em: <https://doi.org/10.1016/j.clinbiomech.2007.03.003>.

MIZRAHI, J. et al. Eff€ ect of fatigue on leg kinematics and impact acceleration in long distance running. Human Movement Science, v. 19, p. 139-151, 2000.

MORENO, C. M. C.; LIBERALI, R.; NAVARRO, F. Obesidade e exercício físico: os benefícios do exercício intermitente de alta intensidade no processo de emagrecimento. Revista Brasileira de Obesidade, Nutrição e Emagrecimento, v. 3, n. 16, p. 298-304, 2009. 
PATAKY, T. C. Generalized n-dimensional biomechanical field analysis using statistical parametric mapping. Journal of biomechanics, v. 43, n. 10, p. 1976-1982, 2010.

PATAKY, T. C.; ROBINSON, M. A.; VANRENTERGHEM, J. Vector field statistical analysis of kinematic and force trajectories. Journal of biomechanics, v. 46, n. 14, p. 2394-2401, 2013.

PENNY, W. D. et al. Statistical parametric mapping: the analysis of functional brain images. [s.1.] Elsevier, 2011.

PIERCE, S. J. et al. Prolonged Incremental Tests Do Not Necessarily Compromise VO2max in Well-Trained Athletes. Journal of science and medicine in sport, v. 2, n. 4, p. 356-363, dez. 1999.

ROSS, L. M.; PORTER, R. R.; DURSTINE, J. L. High-intensity interval training ( HIIT ) for patients with chronic diseases. Journal of Sport and Health Science, v. 5, n. 2, p. 139-144, 2016.

SILER, W. L.; MARTIN, P. E. Changes in Running Pattern during a Treadmill Run to Volitional Exhaustion: Fast versus Slower Runners. International Journal of Sport Biomechanics, v. $7, \quad$ n. 1, p. 12-28, 1991. Disponível em: <https://journals.humankinetics.com/view/journals/jab/7/1/article-p12.xml>.

SLOTH, M. et al. Effects of sprint interval training on VO2max and aerobic exercise performance: A systematic review and meta-analysis. Scandinavian Journal of Medicine \& Science in Sports, v. 23, n. 6, p. 341-352, 2013.

TREMBLAY, A.; SIMONEAU, J. A.; BOUCHARD, C. Impact of exercise intensity on body fatness and skeletal muscle metabolism. Metabolism, v. 43, n. 7, p. 814-818, 1994.

TURCOTTE, L. Lipid metabolism during exercise. In: Exercise Metabolism. Champaing: Human Kinects, 1995. p. 99-130.

WHITING, W. C.; ZERNICKE, R. F. Biomecânica funcional e das lesões musculoesqueléticasRio de Janeiro, RJ: Guanabara Koogan, , 2009.

WINKELMANN, Z. K. et al. Risk Factors for Medial Tibial Stress Syndrome in Active Individuals: An Evidence-Based Review. Journal of athletic training, v. 51, n. 12, p. 1049-1052, dez. 2016.

WINTER, D. A. Biomechanics and motor control of human movement. [s.l.] John Wiley \& Sons, 2009.

WU, G. et al. ISB recommendation on definitions of joint coordinate system of various joints for the reporting of human joint motion-part I: ankle, hip, and spine. Journal of biomechanics, v. 35, n. 4, p. 543-548, 2002.

ZWESLOOT, K. A. . et al. et al. High-intensity interval training induces a modest systemic inflammatory response in active, young men. Journal of Inflammation Research, v. 7, p. 9-17, 2014. 
9. ANEXO A - Aprovação do comitê de ética em pesquisa

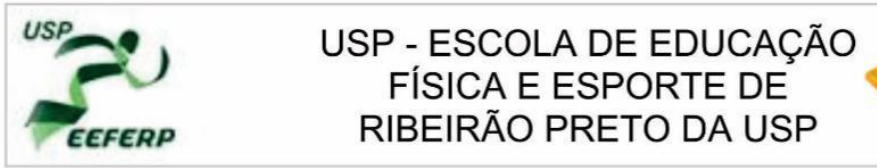

\section{PARECER CONSUBSTANCIADO DO CEP}

\section{DADOS DO PROJETO DE PESQUISA}

Título da Pesquisa: Análise Cinemática dos esforços de corrida durante uma sessão de Treinamento Intervalado de Alta Intensidade

Pesquisador: VITOR MARQUETI ARPINI

Área Temática:

Versão: 3

CAAE: 70232317.2 .0000 .5659

Instituição Proponente: UNIVERSIDADE DE SAO PAULO

Patrocinador Principal: Financiamento Próprio

DADOS DO PARECER

Número do Parecer: 2.311 .522

Apresentação do Projeto:

Vide versão anterior.

Objetivo da Pesquisa:

Vide versão anterior.

Avaliação dos Riscos e Benefícios:

Vide versão anterior.

Comentários e Considerações sobre a Pesquisa:

Vide versão anterior.

Considerações sobre os Termos de apresentação obrigatória:

Não há pendências.

Conclusões ou Pendências e Lista de Inadequações:

Não há pendências.

Considerações Finais a critério do CEP:

O projeto encontra-se APROVADO para execução. Pedimos atenção aos seguintes itens:

1) De acordo com a Resolução CNS n. ${ }^{\circ} 466 / 2012$, o pesquisador deverá apresentar relatórios semestrais

Endereço: Avenida Bandeirantes, 3900

Bairro: VILA MONTE ALEGRE

UF: SP

CEP: $14.040-907$

Telefone: (16)3315-0494

E-mail: cep90@usp.br 


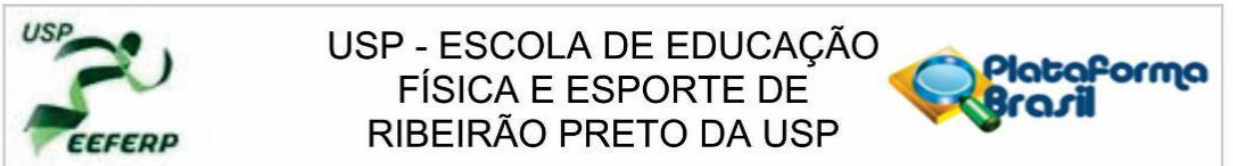

Continuação do Parecer: 2.311 .522

(parciais e final, em função da duração da pesquisa).

2) Eventuais emendas (modificações) ao protocolo devem ser apresentadas, com justificativa, ao CEP de forma clara e sucinta, identificando a parte do protocolo a ser modificada;

3) Sobre o TCLE: caso o termo tenha DUAS páginas ou mais, lembramos que no momento da sua assinatura, tanto o participante da pesquisa (ou seu representante legal) quanto o pesquisador responsável deverão RUBRICAR todas as folhas, colocando as assinaturas na última página.

4) Toda equipe de pesquisa deve fazer treinamento para estar apta a prestar socorros de urgência.

Este parecer foi elaborado baseado nos documentos abaixo relacionados:

\begin{tabular}{|c|c|c|c|c|}
\hline Tipo Documento & Arquivo & Postagem & Autor & Situação \\
\hline $\begin{array}{l}\text { Informações Básicas } \\
\text { do Projeto }\end{array}$ & $\begin{array}{l}\text { PB_INFORMAÇŐES_BÁSICAS_DO_P } \\
\text { ROJETO 890853.pdf }\end{array}$ & $\begin{array}{c}02 / 10 / 2017 \\
15: 28: 25\end{array}$ & & Aceito \\
\hline Outros & CartaResposta_Consideracoes_3.pdf & $\begin{array}{c}02 / 10 / 2017 \\
15: 27: 42 \\
\end{array}$ & $\begin{array}{l}\text { VITOR MARQUETI } \\
\text { ARPINI }\end{array}$ & Aceito \\
\hline $\begin{array}{l}\text { Projeto Detalhado / } \\
\text { Brochura } \\
\text { Investigador }\end{array}$ & $\begin{array}{l}\text { ProjetoMestradoComitedeEtica02_10_1 } \\
\text { 7_VitorMarquetiArpini_correcoes.pdf }\end{array}$ & $\begin{array}{l}02 / 10 / 2017 \\
15: 26: 47\end{array}$ & $\begin{array}{l}\text { VITOR MARQUETI } \\
\text { ARPINI }\end{array}$ & Aceito \\
\hline $\begin{array}{l}\text { TCLE / Termos de } \\
\text { Assentimento / } \\
\text { Justificativa de } \\
\text { Ausência } \\
\end{array}$ & $\begin{array}{l}\text { TCLE_HIIT_VitorMarquetiArpini_Comite } \\
\text { deEtica_modificado.docx }\end{array}$ & $\begin{array}{c}26 / 09 / 2017 \\
14: 27: 48\end{array}$ & $\begin{array}{l}\text { VITOR MARQUETI } \\
\text { ARPINI }\end{array}$ & Aceito \\
\hline $\begin{array}{l}\text { Declaração de } \\
\text { Instituição e } \\
\text { Infraestrutura }\end{array}$ & Termo_de_Infraestrutura_FAPESP.pdf & $\begin{array}{c}03 / 04 / 2017 \\
10: 49: 24\end{array}$ & $\begin{array}{l}\text { VITOR MARQUETI } \\
\text { ARPINI }\end{array}$ & Aceito \\
\hline Folha de Rosto & $\begin{array}{l}\text { folhaDeRosto_VitorMarquetiArpini_Mestr } \\
\text { ado.pdf }\end{array}$ & $\begin{array}{c}03 / 04 / 2017 \\
10: 47: 03 \\
\end{array}$ & $\begin{array}{l}\text { VITOR MARQUETI } \\
\text { ARPINI }\end{array}$ & Aceito \\
\hline
\end{tabular}

Situação do Parecer:

Aprovado

Necessita Apreciação da CONEP:

Não

RIBEIRAO PRETO, 03 de Outubro de 2017

Endereço: Avenida Bandeirantes, 3900

Bairro: VILA MONTE ALEGRE

UF: SP Município: RIBEIRAO PRETO

CEP: $14.040-907$

Telefone: (16)3315-0494

E-mail: cep90@usp.br 


\section{APÊNDICA A - Termo de consentimento livre e esclarecido}

\section{$\underline{\text { Termo de Consentimento Livre e Esclarecido }}$}

Prezado(a) Senhor(a),

Você sendo convidado a participar da pesquisa intitulada "Análise cinemática na corrida intervalada de alta intensidade". O objetivo desse estudo é identificar quais alterações cinemáticas e eletromiográficas ocorrem em um protocolo de HIIT até a exaustão voluntária em praticantes recreacionais.

Para participar deste estudo, você deverá fazer uma visita no Laboratório de Biomecânica e Controle Motor (LaBioCoM) da Escola de Educação Física e Esporte na USP/Ribeirão Preto. Inicialmente, serão coletadas medidas de altura, massa corporal, pressão arterial e frequência cardíaca. Em seguida você irá realizar o seguinte teste: 1) Determinação da velocidade pico em esteira (VPE), por meio de teste incremental na esteira rolante, até o seu cansaço máximo, com duração máxima de 30 minutos, podendo variar para menos. Após 48 horas, você realizará o protocolo de Treinamento Intervalado de Alta Intensidade (HIIT), que consiste em corridas rápidas e curtas (sprints), com $30 \mathrm{~s}$ de duração e $15 \mathrm{~s}$ de recuperação passiva (parado), a uma velocidade de $120 \%$ da encontrada no teste incremental. Para realização desse protocolo serão colocados marcadores refletivos nos seguintes locais: tronco, braços, pernas e pé. O procedimento será filmado e terá duração de aproximadamente 15 minutos.

Você não será submetido(a) a nenhum procedimento sem o seu conhecimento e consentimento, e pode sair desta pesquisa a qualquer momento, sem nenhum prejuízo, se comprometendo apenas a comunicar previamente os responsáveis pela pesquisa.

Você pode não ter benefícios diretos com a pesquisa, mas os resultados obtidos serão importantes para ampliar os conhecimentos e fortalecer a área de pesquisa sobre as alterações cinemáticas nos exercícios intervalados de alta intensidade no público recreacional. Esse conhecimento poderá ainda contribuir para o desenvolvimento de melhores programas de treinamento desse exercício físico.

Os riscos envolvidos com a sua participação na pesquisa são mínimos e envolvem a eventual ocorrência de quedas que será minimizada pela presença de um experimentador próximo a você durante toda a realização da tarefa. Além disso, algumas pessoas podem apresentar vermelhidão temporária na pele devido ao contato com o marcador no corpo, mas isso desaparecerá logo após o término do experimento. No caso de queda, medidas de primeiros socorros serão tomadas, assim como seu encaminhamento para o serviço de saúde.

A sua identidade e todas as informações adquiridas no estudo são confidenciais e o seu nome não será divulgado em momento algum. Nas tarefas com filmagens, as imagens também serão confidenciais e ficarão armazenadas em um banco de dados seguro. Essas imagens serão utilizadas para análise do movimento. 
Não existe nenhum tipo de pagamento que possa beneficiá-lo(a) em função da sua participação neste estudo. A participação nesta pesquisa, não irá te trazer despesas ou custos. Caso tenha eventuais despesas ou custos (tais como transporte e alimentação), elas serão ressarcidas quando necessário pelo pesquisador responsável. Você terá garantia de indenização diante de eventuais danos decorrentes da pesquisa conforme as Leis vigentes no país.

Não existe nenhum tipo de seguro de saúde ou de vida que possa beneficiá-lo(a) em função da sua participação neste estudo. A participação nesta pesquisa, não irá te trazer despesas ou custos.

A sua participação é voluntária e pode interrompê-la a qualquer momento sem prejuízo algum. Seus dados poderão ser excluídos deste estudo em caso de coleta incompleta ou não adequação dos dados ao objetivo deste trabalho.

As informações obtidas nesta pesquisa não serão associadas ao seu nome ou vistas por outras pessoas sem sua prévia autorização. Suas informações serão utilizadas para fins estatísticos ou científicos e sua privacidade e anonimato serão resguardados. A utilização dos seus dados se restringe unicamente a essa pesquisa.

Após preencher e assinar o termo de consentimento, você receberá uma via do mesmo, como de direito.

$\mathrm{Eu}$,

portador do $\mathrm{RG} \mathrm{n}^{\mathrm{O}}$ , residente à , $\mathrm{n}^{\mathrm{o}} \ldots$, Complemento:

Bairro: Cidade: aceito participar, voluntariamente, na presente pesquisa sob a responsabilidade do Pós Graduando Vitor Marqueti Arpini e do Prof. Dr. Paulo Roberto P. Santiago.

Ribeirão Preto, de de 
11. APÊNDICE B - Ficha de Coleta

Nome:

Data:

FCrep:

\begin{tabular}{|l|l|l|}
\hline No SPRINT & FC & PSE \\
\hline & & \\
\hline & & \\
\hline & & \\
\hline & & \\
\hline & & \\
\hline & & \\
\hline & & \\
\hline & & \\
\hline & & \\
\hline & & \\
\hline & & \\
\hline & & \\
\hline & & \\
\hline & & \\
\hline & & \\
\hline & & \\
\hline & & \\
\hline
\end{tabular}

